

\title{
A METHODOLOGY FOR THE COMPARATIVE ASSESSMENT OF THE SATELLITE POWER SYSTEM (SPS) AND ALTERNATIVE TECHNOLOGIES
}

January 1980

\section{U.S. Department of Energy}

Office of Energy Research

Satellite Power System Project Division

DOE/NASA

SATELLITE POWER SYSTEM

Concept Development and

Evaluation Program 


\section{DISCLAIMER}

This report was prepared as an account of work sponsored by an agency of the United States Government. Neither the United States Government nor any agency Thereof, nor any of their employees, makes any warranty, express or implied, or assumes any legal liability or responsibility for the accuracy, completeness, or usefulness of any information, apparatus, product, or process disclosed, or represents that its use would not infringe privately owned rights. Reference herein to any specific commercial product, process, or service by trade name, trademark, manufacturer, or otherwise does not necessarily constitute or imply its endorsement, recommendation, or favoring by the United States Government or any agency thereof. The views and opinions of authors expressed herein do not necessarily state or reflect those of the United States Government or any agency thereof. 


\section{DISCLAIMER}

Portions of this document may be illegible in electronic image products. Images are produced from the best available original document. 


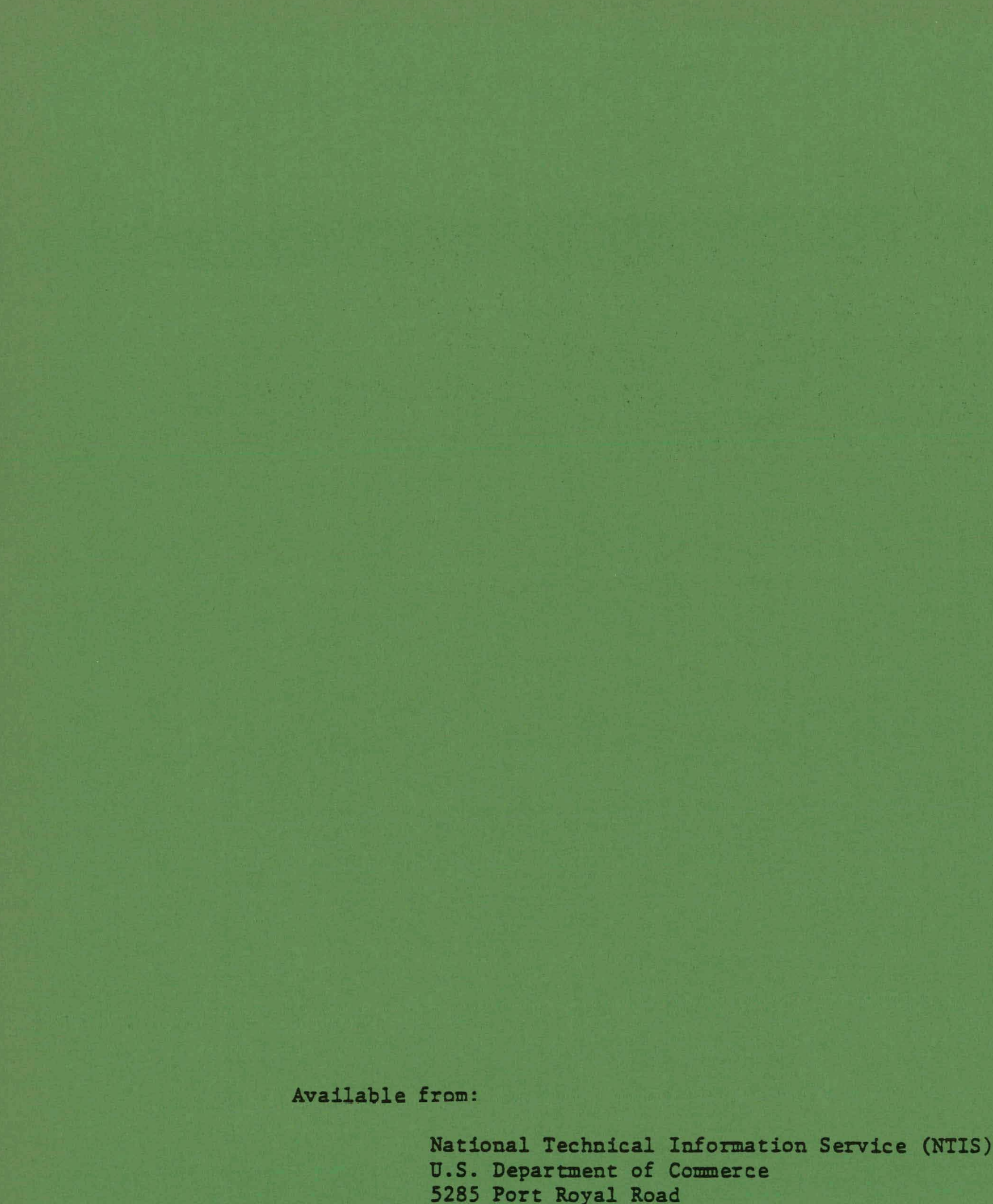

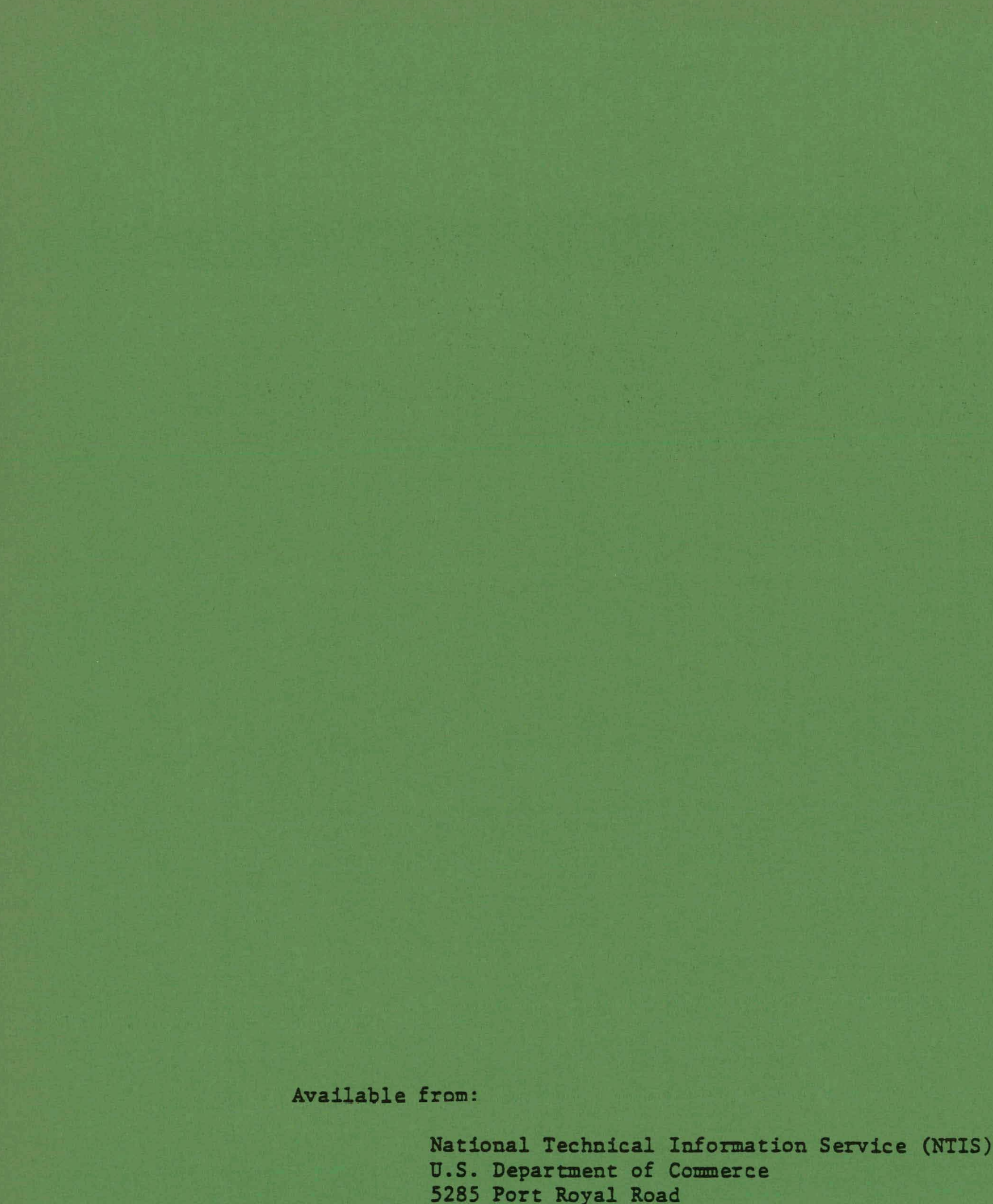

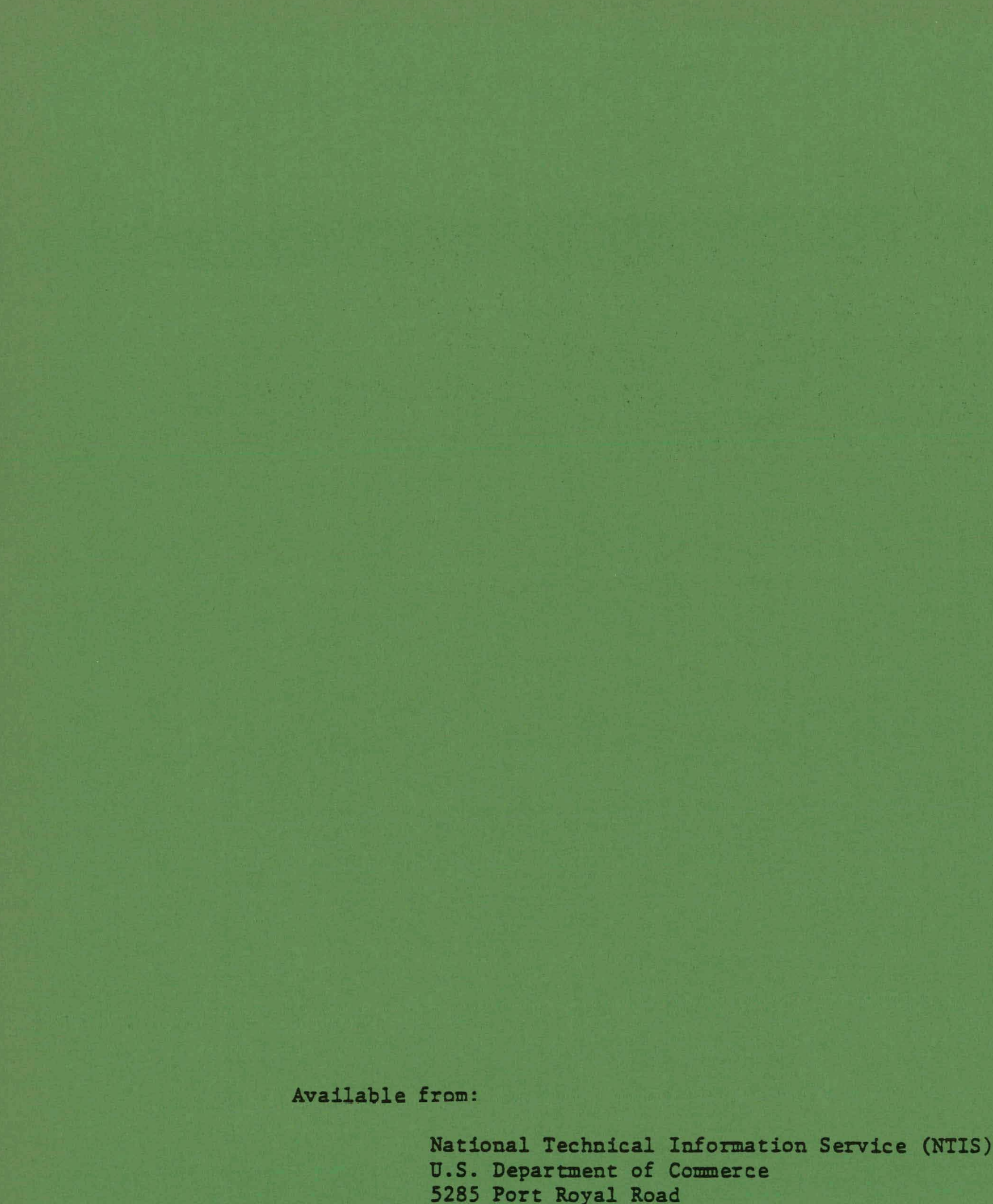

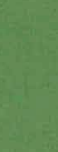

$x^{2}+x^{2}$

.


Dist. Category UC-11, 13, $62,63,97 \mathrm{c}$

\section{A METHODOLOGY FOR THE COMPARATIVE ASSESSMENT OF THE SATELLITE POWER SYSTEM (SPS) AND ALTERNATIVE TECHNOLOGIES}

January 1980

Prepared by:

T. Wolsko, W. Buehring, R. Cirillo, J. Gasper, L. Habegger,

K. Hub, D. Newsom, M. Samsa, E. Stenehjem, and R. Whitfield

Integrated Assessments and Policy Evaluations Group

Energy and Environmental Systems Division

Árgonne National Laboratory

Argonne, Illinois 60439

Under Contract No. 31-109-ENG-38

Prepared for:

U.S. Department of Energy

Office of Energy Research

Satellite Power System Project Division

Washington, D.C. 20545

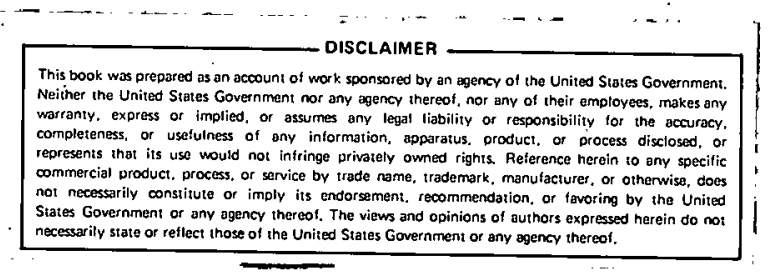

\section{DOE/NASA}

SATELLITE POWER SYSTEM

Concept Development

and

Evaluation Program 


\section{THIS PAGE \\ WAS INTENTIONALLY \\ LEFT BLANK}


The authors are grateful to the following reviewers who contributed to this report through their constructive comments: M.R. Riches and F.A. Koomanoff, Department of Energy; R. Ayres, Carnegie-Mellon University; S. Cohen, TRW; and the members of the Comparative Assessment Review Committee: J.G. Asbury, Argonne National Laboratory; R.E. Bailey, Ohio State University; R.W. Bossert, New York State Consumer Protection Board; K. Bossong, Citizens' Energy Project; G. Deloss, Environmental Policy Center; G.A. Kent, Glenn A. Kent Associates; B.D. LaMar, Argonne National Laboratory; A. Manne, Stanford University; T.J. Nagel, American Electric Power Service Corporation; and G.A. Tolley, University of Chicago. However, the reviewers listed do not necessarily agree with all of the methods described herein. 
THIS PAGE

\section{WAS INTENTIONALLY LEFT BLANK}


PREFACE. $\ldots \ldots \ldots \ldots \ldots \ldots \ldots \ldots \ldots \ldots \ldots \ldots \ldots \ldots \ldots \ldots \ldots \ldots \ldots \ldots \ldots$ vii

ABSTRACT. ..................................... 1

1. INTRODUCTION................................ 1

2. ASSESSMENT FRAMEWORK........................... 5

2.1 SELECTION OF COMPARATIVE ISSUES................. 7

2.2 SELECTION OF ENERGY ALTERNATIVES.................. 10

2.3 ENERGY SYSTEM CHARACTERIZATION.................... 13

2.4 SIDE-BY-SIDE ANALYSIS OF ENERGY SYSTEMS............ 15

2.5 ALTERNATIVE FUTURES ANALYSIS.................... 18

2.6 ASSESSMENT INTEGRATION AND AGGREGATION TECHNIQUES...... 23

3. METHODOLOGY FOR COMPARATIVE ASSESSMENT............... 27

3.1 COST AND PERFORMANCE....................... 28

3.2 ENVIRONMENTAL IMPACTS........................ 33

3.2.1 Health and Safety Effects.................. 33

3.2.2 Welfare Effects......................... 43

3.3 RESOURCES............................... 47

3.3.1 Land Use............................. 47

3.3.2 Critical Materials....................... 48

3.3.3 Energy Balance........................ 52

3.3.4 Water Resources.......................... 55

3.3.5 Comparative Labor Effects................... 59

3.4 ECONOMIC AND SOCIETAL IMPACTS................... 59

3.4 .1 Macroeconomir Fffer.t..................... 59

3.4 .2 Socioeconomic Effects.................... 62

3.5 InStitutional impacts....................... 64

REFERENCES..................................... 67 
2.1 Candidate Alternative Technologies..................... 11

2.2 Preliminary Energy Alternatives..................... 11

2.3 Scenario Characteristics of Energy Demand and Supply........ 21

3.1 Units of Measure for Cost Analysis................... 31

3.2 Nominal Values in Cost Analysis...................... 34

3.3 Economic Work Sheet............................ 35

3.4 Qualitative Indicators and Units of Measure of Public and Occupational Health and Safety Impacts per Unit Output...... 38

3.5 Components of the Comparative Assessment of Health and

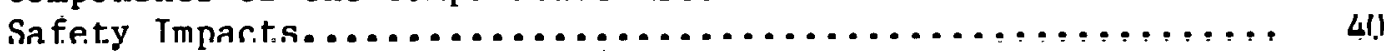

3.6 Units of Measure for Water Resource Requirements and Impacts of Energy Systems......................... 57

3.7 Units of Measure for Regional Availability and Quality of Water for Energy Production..........................

\section{LIST OF FIGURES}

1.1 Functional Groups in the Satellite Power System Concept Development and Evaluarion Program..................... 2

2.1 Analytic Sequence for the Comparative Assessment........... 6

2.2 Classification System of the Comparative Assessment......... 8

2.3 Energy system Characterization....................... 14

2.1 Sidc-by-Eide Analysis............................ 17

2.5 Alternative Futures Analysis......................... 20

3.1 Flowchart for General Methodology.................... 28

3.2 Fl nwrhart for rinst and Value Calculation... ........... 29

3.3 Pathway of Energy Activities, Impacts, and Welfare Effects... 45 
The work reported here was sponsored by DOE and NASA as part of their Satellite Power System Concept Development and Evaluation Program (SPS-CDEP). One of the objectives of that program is the comparison of the technological, environmental, societal, and economic aspects of the SPS with those of selected alternative energy systems after the year 2000.

The purpose of this work was the formulation of a methodology for the comparative assessment portion of the SPS-CDEP. This methodology is an initial prescription, rather than a program plan, for performing a comparative assessment and is expected to be. further developed and refined as the assessment proceeds. The scope of this methodology does not include any specific program limttations; therefore, program planners must consider time and budgetary constraints. when using this work as a reference.

The results of the comparative assessment are to be used as input to the overall evaluation program. That program will provide information to the energy policy data base, which will be used in decision making on post1980 research and development programs for the SPS. 
ABSTRACT

This report is a description of the initial methodology for the Comparative Assessment of the Satellite Power System Concept Development and Evaluation Program of NASA and DOE. Included are study objectives, issue identification, units of measurement, methods, and data bases. The energy systems concerned are the satellite power system, several coal technologies, geothermal energy, fission, fusion, terrestrial solar systems, and ocean thermal energy conver sion. Guidelines are suggested for the characterization of these systems, side-by-side analysis, alternative futures analysis, and integration and aggregation of data. The bulk of this report is a description of the methods for assessing the technical, economic, environmental, societal, and institutional issues surrounding the deployment of the selected energy technologies.

\section{INTRODUCTION}

The purpose of the Satellite Power System Concept Development and Evaluation Program (SPS-CDEP*) is to gather information that will reduce uncertainty and clarify decision making regarding the continued development of a satellite power system technology after fiscal year 1980 . The SPS evaluation program is divided into five functions (Fig. 1.1): 1) systems definition, 2) evaluation of the environmental, health, and safety factors of the SPS, 3) evaluation of societal issues, 4) a comparative assessment (CA) of alternative energy systems, and 5) planning and analysis. The objectives of these functional categories are as follows:

- Systems Definllion: Froduce a reference SPS sonrept for the assessment of technical possibility, environmental and social acceptability, and economic viability.

- Environmental Assessment: Determine the potential impact of the SPS on the environment and on the health and safety of the SPS workers and the general public.

- Societal Assessment: Determine the international, institutional, resource, and other impacts that might inhibit or constrain the deployment of SPS technology.

- Comparative Assessment: Compare the SPS with selected near-term and advanced energy technologies at the time of implementation (2000).

\footnotetext{
* Satellite Power System (SPS) Concept Development and Evaluation Program Plan, July 1977-August 1980, National Aeronautics and Space Administration and U.S. Depàrtment of Energy (February 1978).
} 


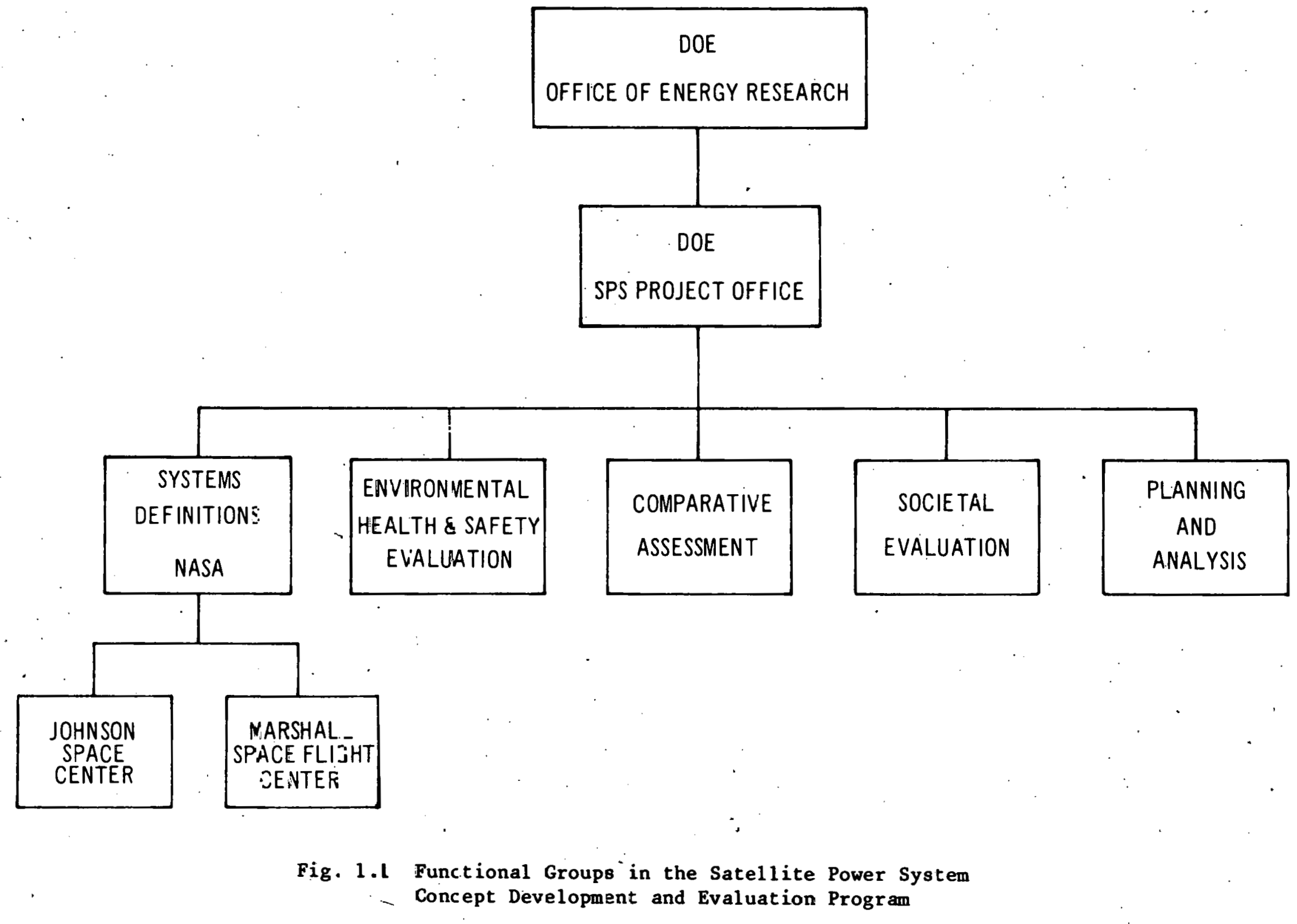


- Planning and Analysis: Provide proper direction to the overall SPS-CDEP or to any of its parts.

The environmental, societal, and comparative assessments of the SPS-CDEP will provide feedback to the systems definition activity, to assist in the development of a more viable SPS concept.

Comparative Assessment

The comparative assessment has been divided into four parts:

1. Comparative Methodology: The framework and methods of evaluation are established.

2. Energy Alternatives Characterization: The terrestrial alternatives are defined in terms of their cost, performance, and environmental and societal attributes in the post-2000 era.

3. Comparative Evaluations: The information compiled in the comparative assessment and in other parts of the SPS program is used to evaluate the SPS and other technologies.

4. Management and Integration: Data from other parts of the assessment are assembled and integrated into a form useful to decision makers.

The major inputs to the comparative assessment are the results of research conducted on systems designs and on the economic, environmental, and societal aspects of the deployment of the SPS and alternative technologies. The purpose of the comparative assessment is to evaluate and synthesize the information obtained into a consistent format useful for making comparisons between future energy systems.

The results of the comparative assessment will be incorporated into a data base used in policy formulation. To ensure the usefulness of program outputs, several reviews of intermediate and final outputs by experts external to the program have been planned.

\section{Comparative Methodology}

The comparative methodology must perform the following functions: 1) establish a framework of assessment information that incorporates different comparative viewpoints, 2) develop a classification systein in which the environmental, social, and economic issues can be grouped into meaningful categories for the decision maker, 3) identify the units of measure that are 
used to compare the environmental, soclal, and economic issues, 4) establish quantitative and qualitative strategles (approaches, methods, models) of data collection and analysis for an issue assessment, and 5) identify sources of data for the comparative assessment. Published and unpublished sources of information, computerized data bases, and assessments already performed on alternative technologies will be used to form a data base that will serve as a traceable reference point for all comparisons.

The next section describes the four stages of the assessment framework (technology characterization, side-by-side assessment analyses, alternative futures analyses, and assessment integration) and the selection of energy alternatives and 1ssues. Section 3 contains a detailed description of the comparative issues to be studied in the assessment and the units of measure that could be used for comparing these issues. In addition, methods of data collection and analysis and the sources of data for this assessment are discussed. Because it is an initial attempt at a general methodological framework for the comparative assessment and beranse it will bc modified as it is used, this methodology may not reflect the same understanding of the issues as that which will finally result from the assessment activities. 


\section{ASSESSMENT FRAMEWORK}

The purpose of this section is to describe the comparative framework for assessing the technical possibility, economic viability, and social and environmental acceptability of the alternative energy systems and of the SPS at the time of its implementation.

As shown in Fig. 2.1, there are six main analytical procedures for the comparative assessment:

- Comparative issues selection

- Energy alternatives selection

- Energy system characterization

- Side-by-side analysis of energy systems

- Alternative futures analysis

- Integration and aggregation

First, the important issues and alternative energy systems are selected for comparison. Then, the individual energy-system characterizations provide reference data on technology cost and performance, resource use, and residuals. Side-by-side analysis normalizes the energy output from each system and allows the options to be compared on the basis of impact per unit output. The alternative futures analysis incorporates these results into energy supply/demand scenarlus that arc designed to examine specific issues and potential problems. Integration and aggregation of the large amounts of data and Information provided by the analysis should ald decision makers in formulating SPS program recommendations. The comparative assessment framework, as indicated in Fig. 2.1, is a phased sequence of assessmenc sleys designed so that each major element will provide progressively more sophisticated and more detailed information to these dectsion makers.

In each step of the assessment, the effects of the SPS and the alternative technologies are compared in areas such as electrical energy cost and performance, euvironmental impact, resource use, health and safety problems, economic and societal effects, and institutional problems. The results. of the comparisons will be useful in analyzing issues of concern and will serve as input to the final SPS concept assessment, integration, and recommendation process. The following sections describe each step of the comparative assessment framework in more detall. 
TECHNICAL

SPECIFICATIONS
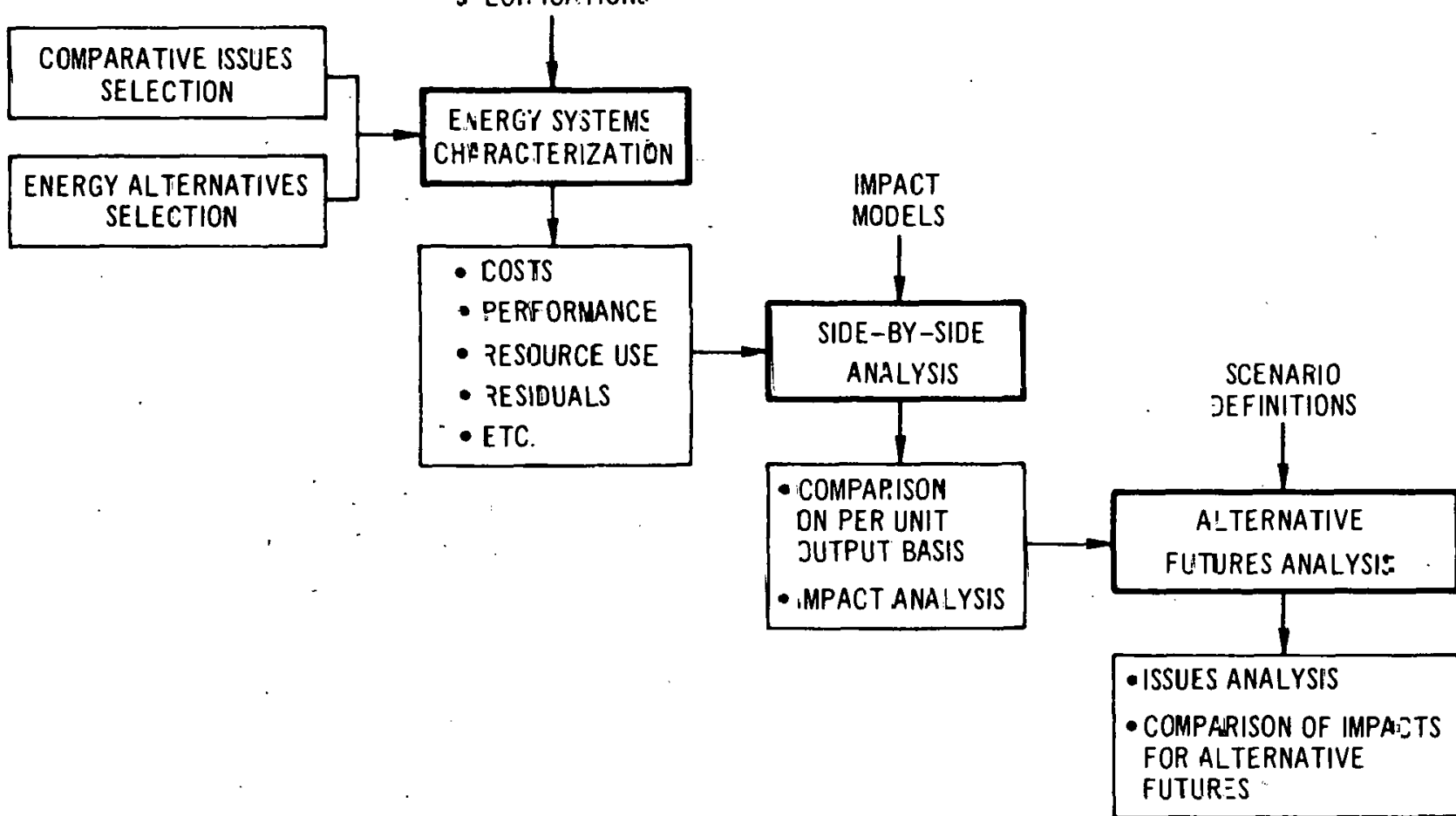

ALTERNATIVE

INTEGRATION/AGGREGATION

METHODOLOGIES

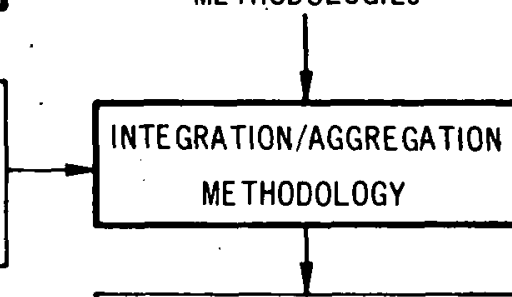

- FRAMEWORK TO ASSIST DECISION MAKER'S RECOMMENDATION

- STRUCTURE TO haNDLE LaRge AmOUNT OF

INFORMATION ON

CONSISTENT BASIS

Fig. ¿.1 Analy \pm ic Sequence for the Comparative Assessment 


\subsection{SELECTION OF COMPARATIVE ISSUES}

Significant issues arising from the deployment of SPS and the alternative terrestrial power systems are identified and described in the process of comparative issues selection. The issues selected for the comparative assessment must not only be general enough to accommodate differences among the alternative technologies, but also specific enough to be truly commensurable. For example, among the energy systems being compared, the SPS ${ }^{1}$ alone entails microwave power transmission.* The interaction of the microwave beam with the atmosphere may cause atmospheric heating, which, in turn, could cause climatological problems or interfere with electromagnetically sensitive systems (e.g., communications transmitters/receivers). In addition, dispersion or scattering of the beam could result in public or occupational health and safety problems. However, since microwave energy is not a feature of any of the alternatives that might be selected for comparison with SPS, the issues cannot be described simply along the lines of microwave problems. Therefore, the approach taken here is to define comparative issues in terms of the stakeholder concerns, that is, climate, welfare, and health and safety issues.

Figure 2.2 illustrates the classification system that was devised for comparing technologies. The issues are grouped under five major categories: cost and performance, environmental, economic/socletal, resource, and institutional. The definitions of some of these categories are unique to this wethodology and therefore should not be confused with definitions reported elsewhere. The relative importance of each of these issue areas is not clear at this point. As the assessment proceeds, some issues may be eliminated on the basis of relative unimportance, unavallability of data, or overlap with other issue areas.

The issues grouped under cost and performance concern the cost of construction, operation, and maintenance of an energy system, in terms of both capital costs and of operation and maintenance costs. Included in this group are system performance issues, e.g., the reliability and overall value of an alternative technolugy lu Llie cumplete energy-supply system.

* The current baseline method for transmitting power from the satellite to earth is via microwave beam. 


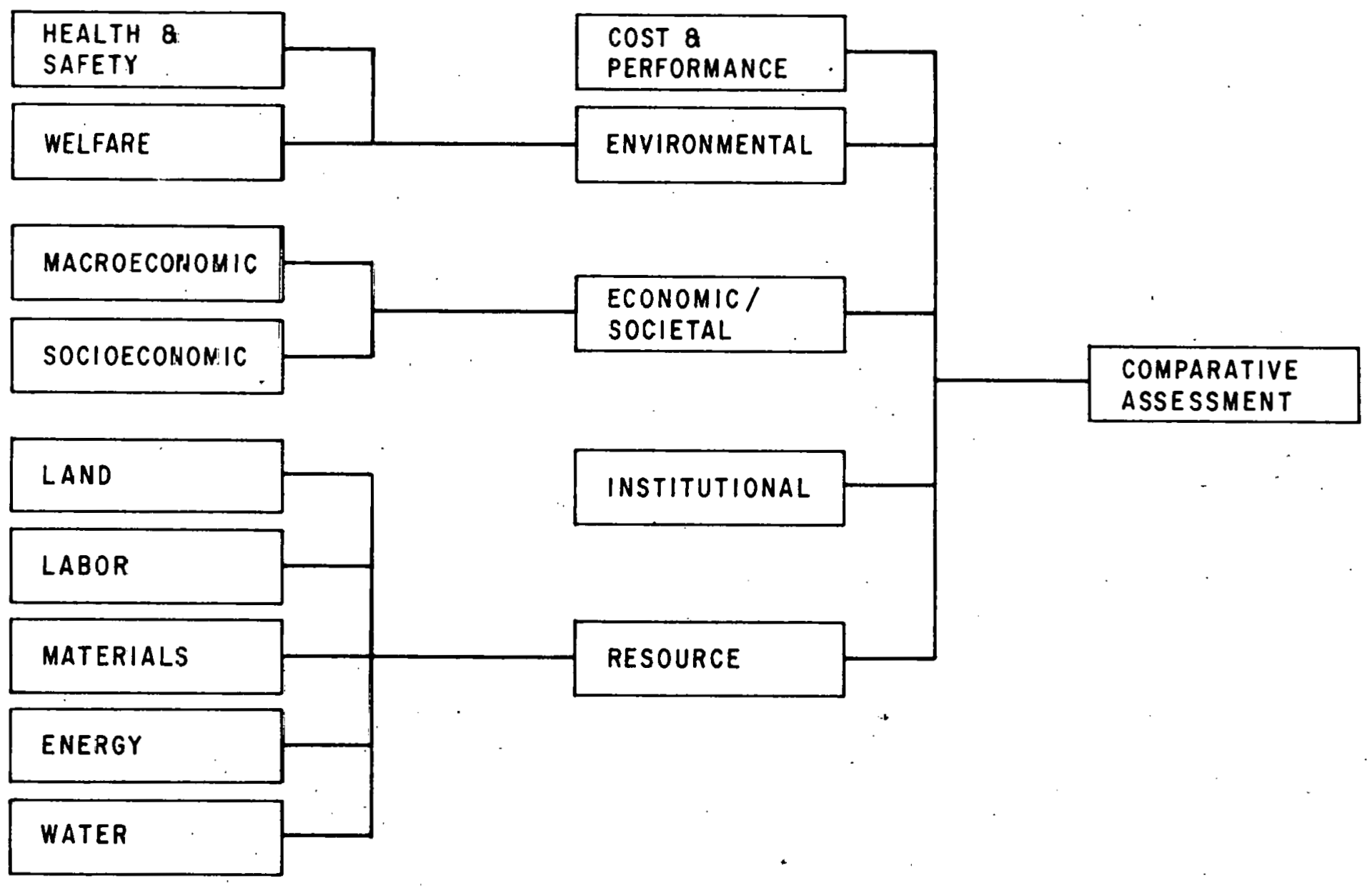

Fig. 2.2 Classifica:ion System of the Comparative Assessment 
Environmental issues are divided into two subcategories: those that directly concern public and occupational health and safety and those that do not directly concern these areas. Environmental issues not directly related to health and safety deal with problems such as damage to buildings from air pollution, loss of radio-frequency communication due to microwave interference, changes in land values resulting from deployment of an energy technology, and crop damage due to climatological changes.

The issues grouped under health and safety are subdivided into those concerning public health and safety and those concerning occupational health and safety. Health basically refers to chronic problems, whereas safety refers to more acute problems such as accidents, spills, and unexpected releases of hazardous pollutants. For the SPS, occupational concerns include the effects of prolonged labor in geosynchronous earth orbit (GEO) and the safe limits for such activity, the risks of large-scale space construction, and the effects of Van Allen belt radiation; occupational concerns for other technologies include accidents during mining, milling, construction, and operation. Public health and safety issues arising from deployment of the SPS are largely associated with the effects of short-term and 1ong-term exposure to low-power density of microwave energy. The issues of fuel transportation accidents, and pollutant and particulate emissions are mainly associated with fossil fuel systems, whereas the effects of radioactive waste and the threat of subversive actions are associated with nuclear oystems.

The category of economic/societal issues is divided into two parts: macroeconomic and socioeconomic effects. The deployment of energy technologies will result in socioeconomic effects (e.g-, temporary and permanent shifts in population, near-term and long-term services, and employment opportunities). The macroeconomic subcategory concerns national economic issues (like balance of trade, effect on the gross national product, and capital demands). Institutional comparisons deal with the effects of existing institutions on the deployment of a technology (regulatory impacts), the institutional changes resulting from the deployment of a technology (e.g., new labor unions, new training programs), and international considerations (e.g., foreign regulation and participation). The resource category includes five subcategories: 1and, labor, materials, energy, and water. Here, key concerns include resource limits, production limits, degree of foreign dependency, and need for new skilled labor. 


\subsection{SELECTION OF ENERGY ALTERNATIVES}

A large number of technologies (listed in Table 2.1), including seven fossil options, three geothermal options, five nuclear technologies, and five solar technologies, were initially considered for selection as alternatives to the SPS. The following criteria were used to arrive at the reduced list of energy alternatives shown in Table 2.2:

- The list must be kept to a minimum because the systems selected will be studied in detail in the energy characterization step (consequently, representative systems from major technology areas were chosen).

- Energy output must be in the form of electricity.

- Commercial availability should be possible after the year 2000.

- The technology must have the capability for baseload operation.

- The technology must have an available source of fuel for many years.

- Design information on the technology must be available.

These criteria allow the inclusion of currently used technologies that have improved performance since their original deployment, as well as the selection of new technologies that are being developed or technologies that are still at the conceptual stage (those for which little engineering design information exists). Note that the selection of alternatives that lack a complete design may cause difficulties in performing the comparative assessment; thus, some technologies may have to be excluded at a later date on the basis of inadequate data.

This preliminary list of energy alternatives groups the technologies Into seven areas. Several methods of producing electricity from coal combustion are included under coal technology. Each of these methods is an improvement over conventional coal combustion environmentally, economically, or technically. These methods will therefore be grouped as one alternative to the SPS with several options in terms of environmental, technical, or economic performance. Due to limited fuel resources and the fact that no new gas- or o11-fired plants are planned, gas and o1l have been eliminated as sources of substantial quantities of electricity in the post-2000 era. 
Table 2.1. Candidate Alternative Technologies

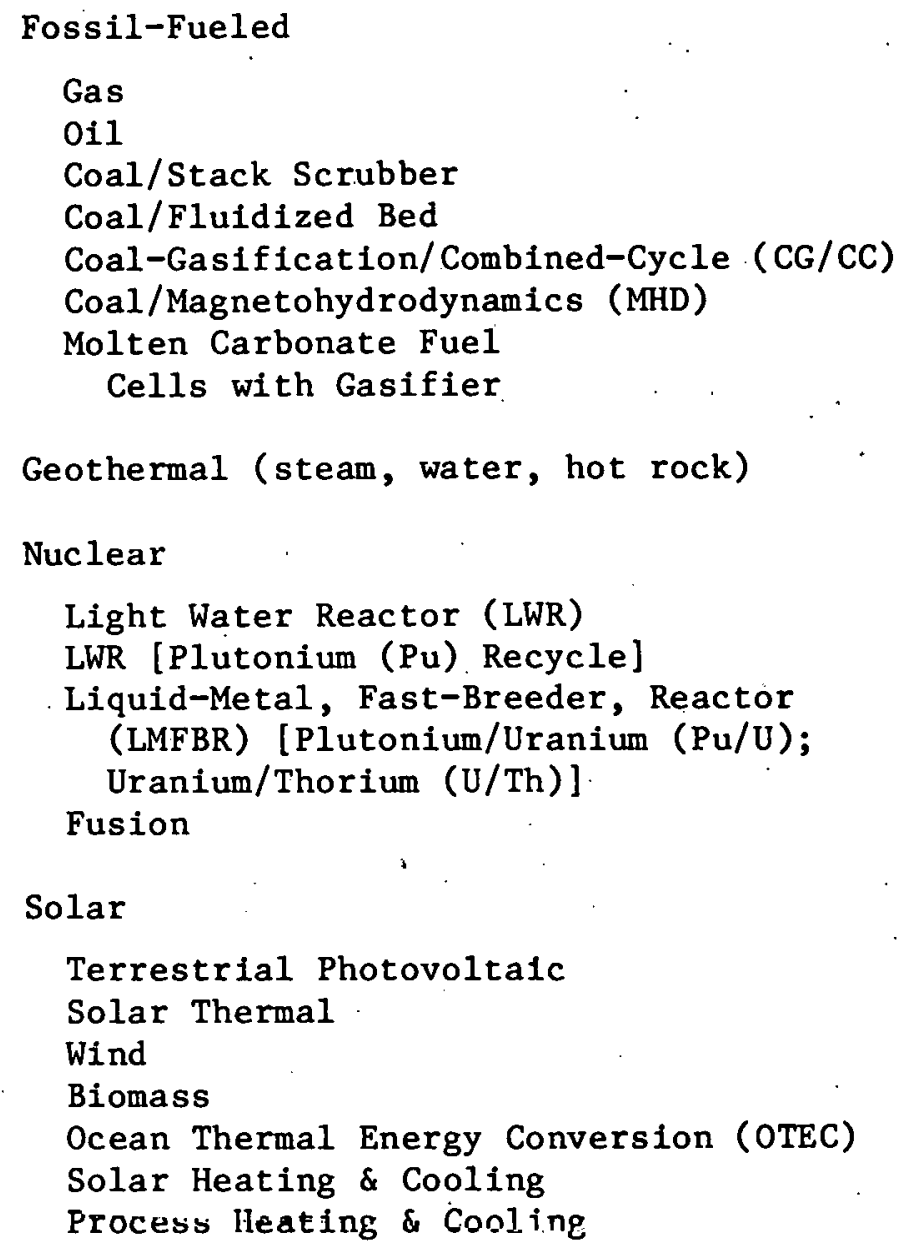

Table 2.2 Preliminary Energy Alternatives

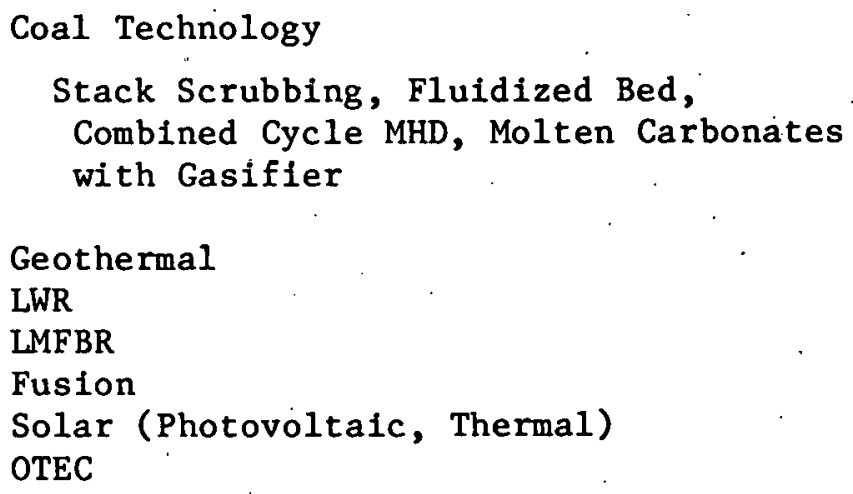


The second alternative to the SPS is the hot rock concept of geothermal energy. Geothermal steam and hot water energy were eliminated as electrical energy sources because in the post-2000 era they will be too small to compete with the other central-station alternatives of electrical generation. (However, these geothermal concepts may still be included in the energy supply picture, as will be discussed later.) The availability of a hot rock geothermal design and proper identification of environmental, societal, technical, and economic issues may make it difficult to properly compare this alternative with the SPS, but it is included in the list of preliminary alternatives at this time. There is a strong possibility that liut rock geothermal energy will be a significant energy source an 2 regional basls.

Decause of different resource demands and environmental problems, two systems of nuclear fission were selected for the assessment: 1ight water reactors (LWR) and liquid-metal, fast-breeder reactors (LMFBR). Plutonium recycle will be considered as an option in the LWR alternative. Several LMFBR options may be included in order to assess the technical, economic, environmental, and societal viability of this technology.

Fusion, which has several potential concepts, was chosen as a separate alternative. The lack of a design and insufficient identification of the envirumental, societal, technical, and economic performance of this alternative may exclude it from the comparative assessment at a later date. However, it would be wrong to exclude fusion from the comparative assessment since it is potentially a huge source of energy.

Two direct solar options should be considered in the prelininary assessment: photovoltaic systems and thermal systems. Since SPS is a central station, baseload type of system, the preliminary comparioon should be to a concral slalion, solar alternative; however, later assessments could include a comparison to a distributed solar lechnology.

The seventh energy alternative to the SPS comprises ocean thermal energy conversion systems (OTEC). Although this type of technology has limited geographic application, it nonetheless can become a significant baseload energy source. 


\subsection{ENERGY SYSTEM CHARACTERIZATION}

Following the selection of energy alternatives and the preliminary selection of comparative issues, the energy system characterizations will provide the basis for the comparative analysis. The objective of energy system characterization is to define and describe reference energy systems that are the principal alternatives. to the SPS. The data for these characterizations will be assembled according to the following criteria:

- Characterizations should use readily available, information.

- Characterizations should be performed and documented by experts.

- Each technology characterization should be internaily consistent.

- The set of characterizations should display overall consistency and facilitate comparisons with the SPS concept.

- Characterizations should be comprehensive enough to allow adequate evaluation of issues (failing this criterion, a candidate technology may have to be dropped from consideration at a later date).

- Characterizations should include the areas of uncertainty in the technology definition.

- Characterizations should be credible to the stakeholder.

Flgure 2.3 lllustrates the relationship of the energy characterizations and the comparative assessment data base. Characterizations consider the complete fuel cycle (1.e., resource extraction, processing, transportation, conversion, and waste disposal) and quantify the effects of the energy supply systems in terms of cost and performance, resource use (1and, water, 1abor, materials) and residuals of the energy systems.

The characterizations of the reference energy systems generally will not attempt to carry the impact analysis beyond quantification of residuals, resource use, and performance. For example, the expected emission of sulfur dloxlde from a coal-fired power plant with scrubbers will be specified. However, the ambient concentrations and associated health effects will not be part of the characterization but will be included in the side-by-side analysis to the extent that they have been quantified. Many of these non-cost issues will be included in the analysis on a qualitative basis. 


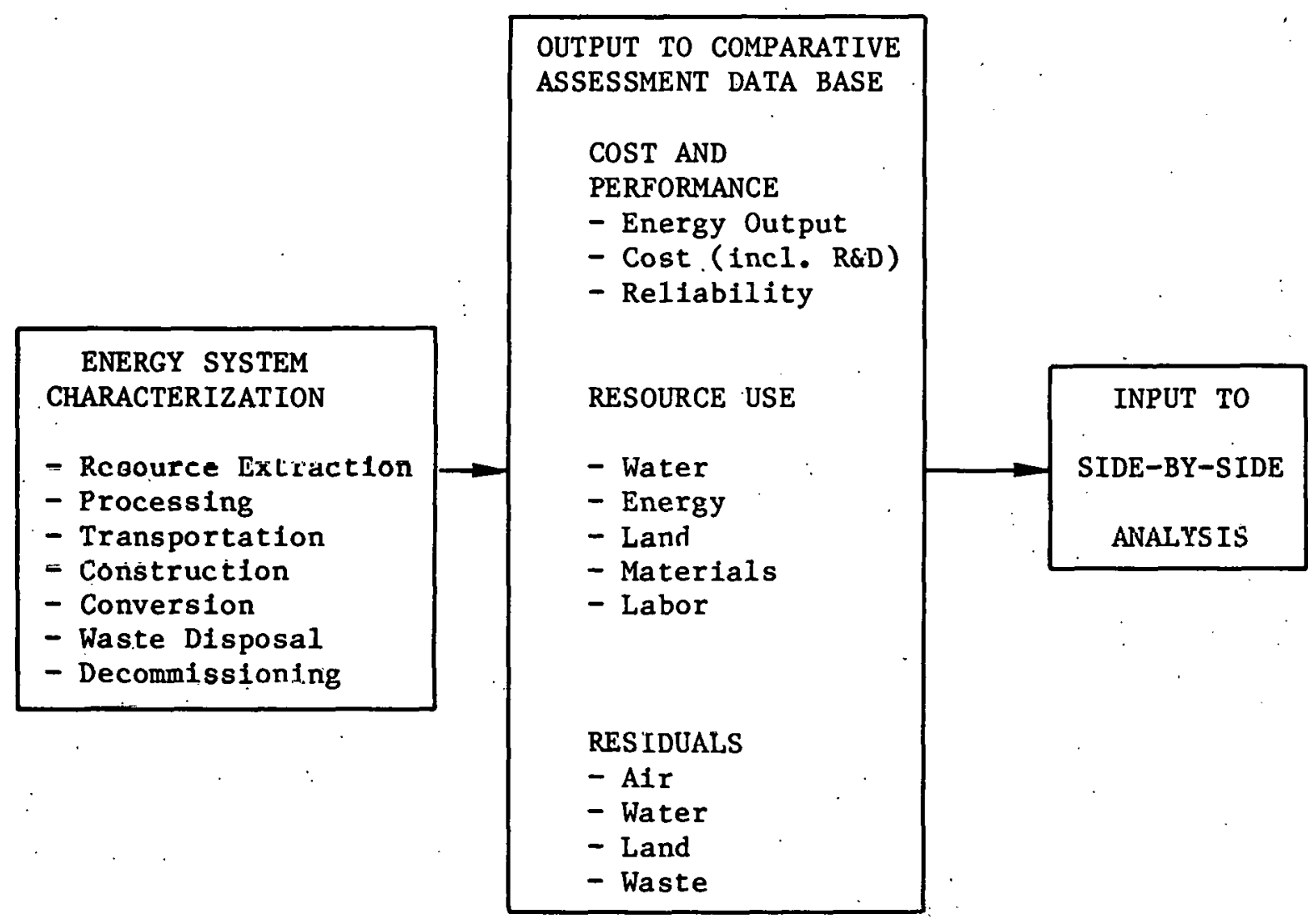

Fig. 2.3 Energy System Characterisation

Since the goal is to compare the SPS and its alternatives at the time of 3PS Implementation, judgments must be made on the technologies avallable, the resources avallable, and the regulatory climate that will exist at that time. For example, the earliest implementation date may be approximately the year 2000. The current world energy situation and U.S. energy policy indicate that large-scale use of natural gas and petroleum for electrical generation is not likely for that time period. (In fact, no new gas- or oll-fired facilities are being ordered.)

Studies ${ }^{2-7}$ that will be helpful in these investigations are available. The well-documented studies by Hittman Assuclates, 2 as part of the Matrix of Environmental Residuals for Energy Systems (MERES) effort, ${ }^{3}$ will be useful for establishing initlal characterizations of current technologies and some advanced concepts. The characterizations will require updating and extension 
to the post-2000 conditions that are established as part of the comparison. A Jet Propulsion Laboratory (JPL) report $^{5}$ and its supporting studies will help to establish the conditions and special considerations associated with an SPS comparison. NASA reference designs, and environmental and societal assessments will be used where appropriate. A MITRE report is available for consideration of solar technologies. ${ }^{7}$ There are many assessments that provide characterization information, but many of these are internally inconsistent or do not provide the basis for consistent traceable reference designs or both.

The output from the characterization phase will serve as basic information for decision makers. However, without further analysis, this data is of limited value, since it will describe alternative systems of varying capacities and will merely list the technology characteristics, resource requirements, and residuals. Therefore, the characterization output will also be used as the foundation for the side-by-side analysis.

\subsection{SIDE-BY-SIDE ANALYSIS OF ENERGY SYSTEMS}

The objective of the side-by-side analysis is to perform an initial comparison of the SPS and its alternatives. This comparison is the initial analytical step of the comparative assessment, and it consists mainly of a listing of information (some detailed, some summary) for each of the energy systems. Information categories cover technical, economic, environmental, health and safety, and societal issues.

A side-by-side comparison tabulates normalized effects. on a consistent basis for inspection and analysis by decision makers and résearchers. Although some elements of side-by-side analysis have been performed for conventional technologies on a comprehensive basis, these have limited applicability to the SPS Concept Development and Evaluation Program because the SPS comparative assessment must be concerned with SPS competitors and thus must analyze technologies and expected conditions after 2000 rather than conventional technologies and current or near-term conditions.

The side-by-side comparison will provide useful but somewhat limited Information for decision makers. Although it uses a nondynamic approach (not. accounting for changing conditions), the comparative assessment includes specific assumptions about certain exogenous economic varlables such as GNP 
growth rates and discount rates, and assumptions about international trade and political relationships, e.g., the absence of major wars and the maintenance of world trade stability. Side-by-side comparison provides a relative listing of impacts and effects of alternative technologies and does not display for the decision maker the regional sensitivity of technology impacts or the synergistic effects of environmental impacts. The side-by-side analysis approach will assume that those variables are "exogenous" and will not attempt to account for their interdependence with the technologies under study through the use of a feedback process. This "partial equilibrium" approach is, in reality, incorrect but methodologically useful because of the quality of the data available for the comparisons and the precision of the comparative methoris.

As shown in Fig. 2.4, the side-by-side analysis accepts the system characteristics of each alternative technology as input. Since technologies differ in characteristics such as nominal capacity, reliability, geographic acceptability, and electrical output, the first step of the side-by-side comparison is to normalize* the system characteristics to some comparable parameter, usually electrical energy output. A proper normalization results in technology descriptions that are internally and thermodynamically consistent, yet which represent the future unit capacity mixes.

The second step of the side-by-side comparison applles impact data, modelo, and uller avallable tools to derive the impacts assnriated with the deployment of the technologies. For example, the technology characterizac1on and normalization tasks provide basic characteristics such as employment and job type requirements for the construction and operation of the alternative teclinulogies. I'his second comparison extends the analysis to the application of accident rates and severity, by job type, to derive and tabulate the normalized person-days lost due to accidents and injurico, ${ }^{*}$ Tlie slde-by-side

*The term "normalized comparison" simply means that quantifiable impacts are expressed in terms of amount per unit output of electrical energy, like a megawatt-year (MWe-yr). Thus, a 5-MWe system that provides energy continuously for one year and expels 1,000 tons of pollutant to the environment in the process will be characterized by the normalized amount of 200 (or $1,000 \div 5$ ) tons of pollutant per MWe-yr of electrical energy; similarly, a - 1-MWe plant that operates for half a year and produces 50 tons of pollutant is assigned the normalized amount of 100 (or $50 \div \frac{1}{2}$ ) tons of pollutant per MWe-yr.

**It is difficult to derive this figure for existing, well-known technologies; extrapolation to future technologies is even more difficult. 


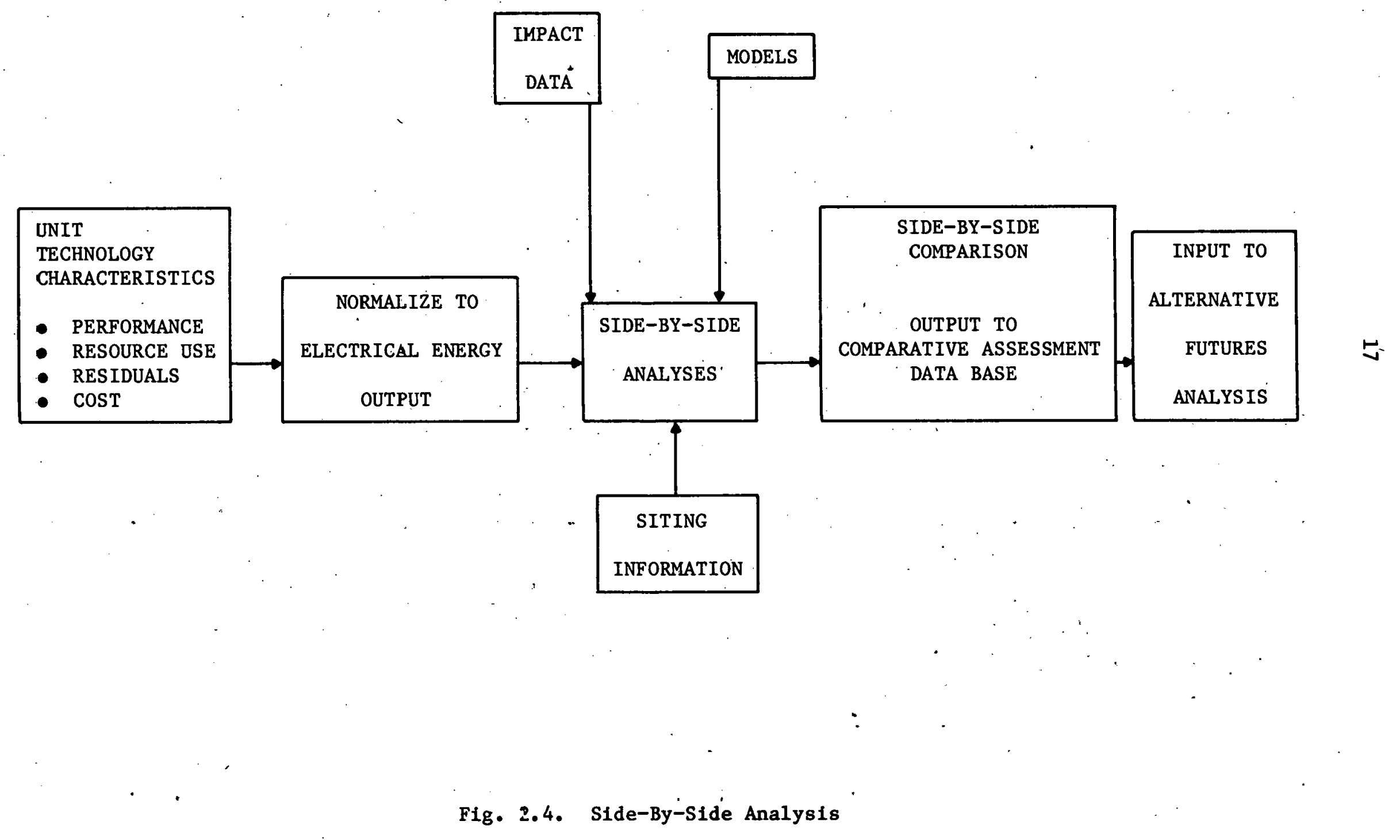


comparison will use the resource requirements, e.g., dollars, labor, and materials, characterized for each technology, and arrive at the relative attractiveness of the alternatives with regard to these characteristics. Similarly, the normalized environmental residuals as characterized for each technology may be modeled for some typical or standard site using available dispersion and pollutant transport models. Local air quality, water quality, and environmental consequences can be derived and tabulated for each technology on the basis of modeling assumptions and population distribution used In the definition of a standard site.

\subsection{ALTERNATIVE FUTURES ANALYSIS}

The alternative futures analysis will place the results of the energy characterizations and side-by-side analysis into a dynamic framework that considers different plausibie future conditions. The analysis will help address impacts that may have synergistic characteristics or that result from multiple plant effects. The results of the analysis will improve understanding of the effects of SPS implementation in key issue areas. An integral part of the analysis is the creation of scenarios (statements about future supply, demand, lifestyle, resources, regulations, etc.), which serve as Inputs to the alternative futures analysis. These scenarios, coupled with Impact models, are used to describe possible alternative futures in terms of parameters such as economic indicators, population, environmental conditions, and Institutional rooponoco.

The primairy objectives of the alternative futures analysis are:

- To provide a comparison of the impacts for different future economic, social, and political conditions.

- To focus on the effects of SPS with respect to selected key issues that will require decisions.

- To provide input for the assessment and integration process and the final comparative assessment.

The following criteria have been selected to guide the cholce of scenarios:

- A small number of scenarios should be used, and they should be feasible and representative.

- They must illustrate a suitably large range of alternatives, policies, and economic and social conditions (or at least those of major concern or interest). 
- They should also organize the results of preceding assessment activities (namely, discussion of issues and interpretation of energy system characterizations).

- They should highlight or identify major categories of issues for further analysis.

- Uncertainty should be included in a consistent and efficient manner.

The alternative futures analysis will indicate the effect of SPS Implementation on several variables (Fig. 2.5), at different levels of aggregation, e.g.,

Leve1 of Aggregation

- World-wide

- National

- Regional

- Local
Variable

$\mathrm{CO}_{2}$ production

Plutonium production

Resource use

Balance of payments

Air quality

Land use

Employment

Ecology

It must be emphasized that the scenarios are not predictions or forecasts but rather are indications of the conditions that would be expected to exist given the judgments concerning scenario definitions and technology availability. This approach is useful because of the large uncertainties present in estimating future conditions. The following are examples of such conditions.

\section{Parameter}

- Socioeconomic conditions

- Lifestyle

- Energy technology availability

- Regulation

- Environment

- Resource constraints

- Issue identification
Examples of Uncertainty

Population, GNP

Impact of conservation on energy demand, decentralized society

LMFBR, coal gasification, terrestrial solar

Pollutant emission standards, amblent air quality standards

$\mathrm{CO}_{2}$, waste heat effects

Uranium, oil and gas, wind, construction materials

What issues will be espectally important in decison making on future energy technology? 


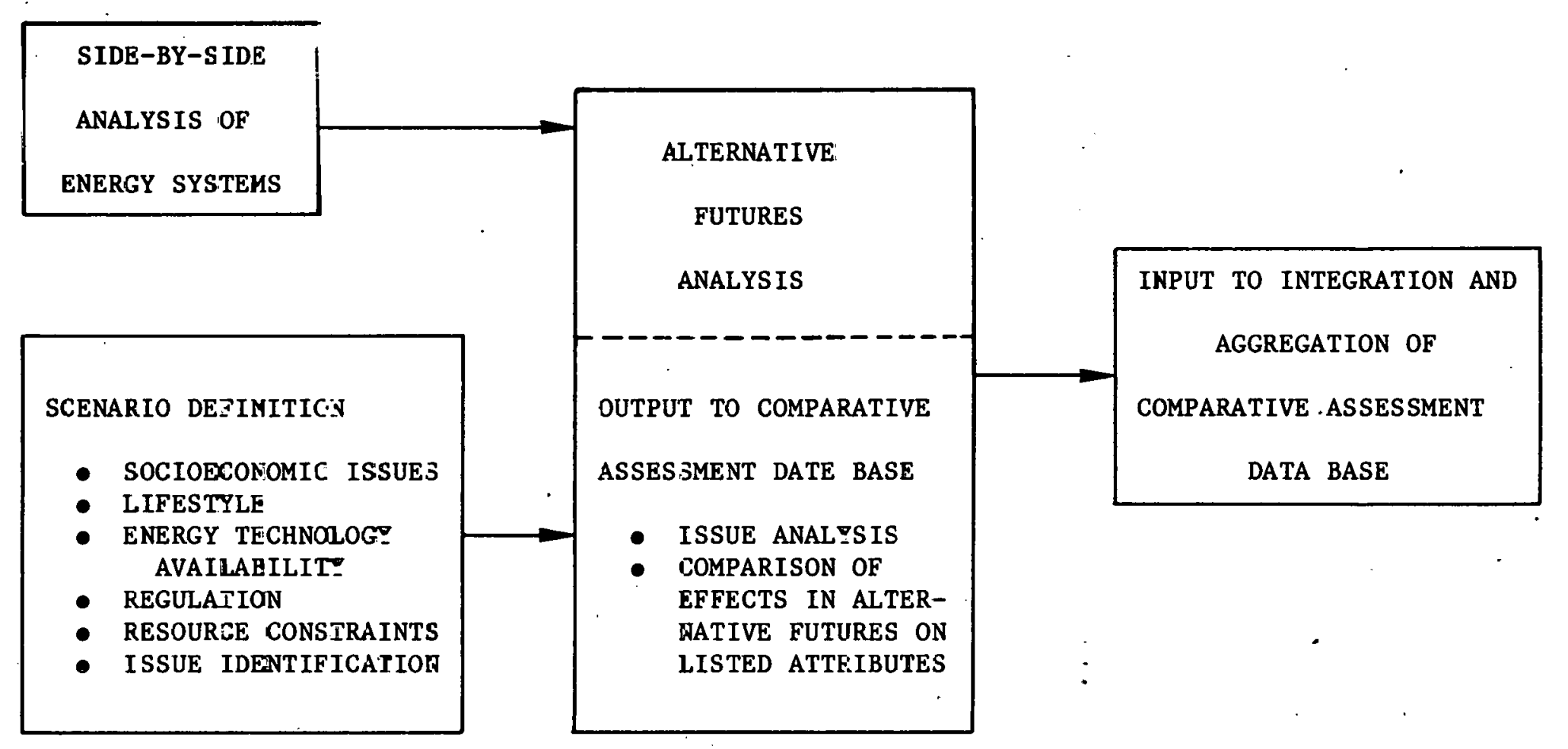

Fig- 2.5. Alternative Futures Analysis 
Uncertainties in these major parameters can be examined using the scenario approach that is based on consistent sets of assumptions and policies. A scenario does not have a probability of occurrence associated with it but instead addresses key issues and, perhaps, reveals other problems that result from that feasible future.

The scenario approach has proven valuable in previous studies of alternative energy futures.8-11 Indeed, one of the benefits of the approach is stimulation of discussion, such as accompanied studies by Meadows et a1., 12 and Lovins. 13,14

Some sample scenario characteristics of energy supply and demand are outlined in Table 2.3. The focus of the SPS evaluation is on the need for electrical power and the alternative methods for satisfying 1 . The use of many decentralized energy options is treated primarily by reducing the energy demand for central-station, baseload electrical generation. However, it might be meaningful to compare the impacts of one or two of the decentralized technologies that might be competitive with SPS, e.g., distributed photovoltaic systems.

The process of scenario construction is described in Fig. 2.5. After identifying the key issues, a set of polfcies and assumptions is formulated

Table 2.3 Scenario Characteristics of Energy Demand and Supply

Demand

1. National Energy Plan II

2. Strong conservation

3. Emphasis on electrical energy

4. Emphasis on nonelectrical energy

5. Emphasis on decentralized options

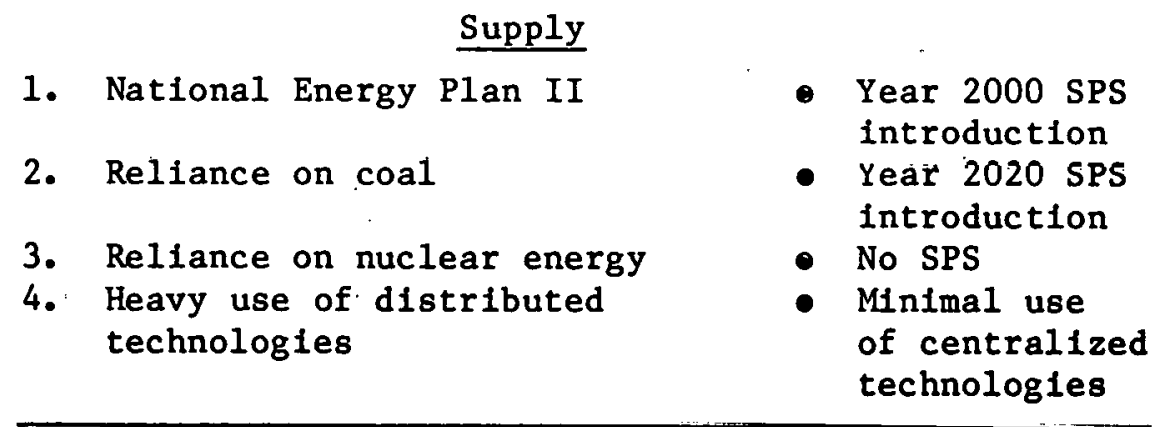


concerning the topics indicated in the figure. A limited number of scenarios can generally illustrate the range of alternatives without overwhelming the analysts and decision makers with data. A classification system such as that shown in Fig. 2.2 aids in organizing the results and in reminding users and analysts of the major categories for comparison and the perceived key issues.

After the specification of the 1ssues, policies, and assumptions that define the scenario, computer models can be used for scenario simulation. This in fact becomes the objective of the modeling effort: to provide the link between the scenarios and what they might mean in the future. The computer models provide an efficient method for quantifying energy supplydemand options and generating a consistent set of scenario effects. The choice of models is governed by the following criteria:

- They must be thoroughly tested and proven reliable.

- They must be readily available and well documented (this precludes the use of models that are proprietary in any manner).

- They must be cost efficient.

One of the first steps in the modeling effort is to establish consistency between the economic and energy characteristics of the scenario. Models reviewed by the Energy Modeling Forum, 15 including PILOT and DRI-Brookhaven models, would provide the desired framework and consistency. Another model that treats substitution between capita1, labor, and encrgy and integrates long-term supply and demand projections is the ETA-MACRO Mode1.16 Following selection and use of one of these models that treat energy-economic interactions; other models may prove useful for developing the associated impacts for each scenario, as measured hy the categorico of effects sliuwn in Fig. 2.2.

The scenario results are not always easy to determine or understand because of complexities such as the following:

- Interdependencies among economic, technological, and ecological characteristics, as mentioned previously.

- Difficulties in Identifying costs and benefits and in assoclating them with specific groups.

- Uncertainties in scenario parameters and changes over time. 
- Difficulties in communicating this complex material.

- Different preference structures for scenario evaluation. 17

The multiple-objective nature of the problem is evident from Fig. 2.2. The tradeoffs between costs, health and safety, land use, air quality, resource use, and jobs are difficult to make and naturally are subject to many different conclusions. Thus, the scenarios can serve not only as indications of the effects of deployment on the listed attributes but also as input to a framework for evaluation. Aggregation techniques; which are addressed in the next section, can help address some of the complexities.

\subsection{ASSESSMENT INTEGRATION AND AGGREGATION TECHNIQUES}

The purpose of this section is to introduce a number of techniques that are potentially useful in the integration and aggregation step of the comparative assessment. The techniques are described in order of sophistication.

The objective of all these integration and aggregation techniques is to analyze the data assembled for the comparison of SPS with other future terrestrial technologies. A further objective is at least to begin reducing the complexity of the decision-making problem, which is aggravated by the large amounts of supporting data for each technology, by varlous techniques that are also described (e.g., by performing some formal tradeoffs or setting prioritles for objectives).

There are a number of criteria that can be used in deciding the appropriate level at which to conduct such integration and aggregation analysis. Some of these criteria are the following:

- The number of measurement categories desired.

- The number of alternatives desired.

- The manner in which viewpolnts over priorities are determined, represented, and incorporated into the decisionmaking process.

- Use of uncertainty.

- Degree of inclusion of interactions between varlables and priorities.

- Suitability for describing dynamic and time-varying conditions. 
The degree of appropriateness of any of these criteria is yet to be determined and depends critically on the degree of quantification of variables and effects that is achievable throughout the entire program. The intent of this program is to be adaptive and thus to utilize all of these techniques as the need arises.

Six techniques were investigated in an initial period of study:* engineering economics, cost-risk-benefit analysis, matrix methods, scoring models, venture analysis, and decision analysis. Each of these offers a unique analytical capability that may be useful in the context of a large cumparison such as that planned for SPS.

Since the cost of generating electric power is a slgnificant tactor in this evaluation, various methods for performing economic analyses were studied.18-20 Popular keywords in the open literature are "engineering economics" and "conventional finance." In such economic analyses, concepts of economic éfficiency, e.g., present value, return on investment, and payback, are important. These techniques are highly popular and well suited for aiding decision making in situations where only the cost variable is important.

However, because of concerns about environmental and social effects and technical feasibility, in addition to economics, there is a need to go beyond the scope of such cost analyses. Cost-risk-benefit analysis21-23 traditionally promises to explicitly include externalities. This is typically done by expressing external costs and internal costs on a common, usually monetary, scale. This can be rather difficult, oopecially when setting a dollar figure on the value of a human life, but it does produce a single number, which reflects the relative value of each alternative, for the particular ect of value judgments chosen.

Matrix methods 24 avoid this problem by simply identifying all the items of concern, whether they are internal or external, qualitative ui quantitative, quantifiable or nonquantifiable. The items are arranged in matrix form to clearly identify alternatives and decision criteria. Some analysts then augment these with index numbers to indicate: (1) the environ-

*The references cited in this section generally provide both theoretical information and examples of applications that should be of use to the reader interested in further detail. 
ment or population affected, and (2) the level or seriousness of the impact. The decision maker must intuitively weigh the output of a matrix method to make a decision if no single alternative dominates the rest. Scoring models 25-27 again push for a bottom line number by assigning weights to each of the factors in the analysis. Then, taking the impact level or a qualitative index describing the level, and multiplying by the scoring weight, an overall score can be determined for each alternative. This score may be used to rank the desirability of the alternatives.

All of the foregoing methods treat uncertainty, a key concern in the SPS evaluation, in a "brute force" fashion. It is usual to perform a sensitivity analysis to test the effects of extreme outcomes. Venture analy= sis 28,29 explicitly includes uncertainty in the analysis by creating a probability distribution for the factors of interest. Usually only one factor is considered, generally an economic efficiency variable. Assuming that one factor is sufficient for comparing alternatives, the decision maker must be able to discern the most preferred probability distribution out of a group of probability distributions. Inclusion of more than one factor, especially externalities like environmental or societal interests, is difficult if not impossible.

Decision analysis ${ }^{30-32}$ also treats uncertainty in an explicit manner while providing the methodology for including any number of factors in the analysis and performing trade-offs between factors. Combining the notions of aggregation from scoring models and uncertainty from venture analysis with the notion of careful quantification of preferences for individual factors results in a powerful method for evaluating complex preference structures. An important example is risk aversion, which is preference for high-probability but low-impact-level risks over low-probability but high-impact-level risks, even though both have the same expected level of impact.

All of these methods are potentially useful for varying degrees or depth of analysis of key issues, comparison of impacts, and evaluation of various scenarios relating to SPS and other future terrestrial alternatives. The degree of appropriateness of any of these methods is yet to be determined and depends critically on the degree of quantification of variables and effects that is achievable throughout the entire program. 


\section{METHODOLOGY FOR COMPARATIVE ASSESSMENT}

The purpose of this section is to describe specific techniques that may be used to perform the assessments within each of the comparative issue categories illustrated in Fig. 2.2 and described in Section 2.2. The methodology described here provides a general assessment framework and does not take into account the realities of future energy program constraints. The methods described here concern the issue selection and energy system characterization steps and will supply modeled impact data for the integration and aggregation steps.

The following format is used to describe each comparative issue assessment: (1) a preliminary description of each issue, including definftions and objectives, (2) an identification of the units of measure for comparing these Issues, (3) a description of avallable methods (1.e., approaches, models, paradigms) to obtain issue comparisons in the selected units of measure, and (4) a preliminary identification of potential data bases (e.g., data, previous assessments, and characterizations).

Final selection of the methods used will be guided by the particular objectives and needs of each issue area. However, the following generalizations can be made:

- Evaluations must produce outputs that are useful to policymakers and decision makers.

- Data and evaluation results must be well documented, self-consistent, and traceable.

- Assessments must be timely.

- Assessments must meet resource constraints.

The general flow of activities involves first a characterization of the issue and its parameters, and specifying scenario conditions is part of this first step. Data from the characterization are then used in computational models that provide some quantification of the issue. Results of such calculations will be analyzed to provide input for program recommendations. Figure 3.1 gives a general flowchart of the methodology. 


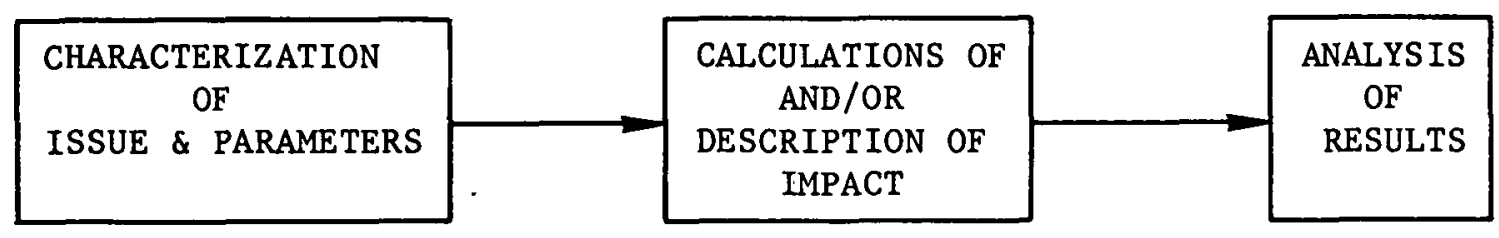

Fig. 3.1 Flowchart for General Methodology

\subsection{COST AND PERFORMANCE}

The objective of the cost and performance methodology is to make the existing cost estimates for the SPS and its alternatives consistent and to provide perspective on the approach and assumptions of procedures for determining SPS costs. Performance levels (i.e., system reliability) of technologies in electric utility systems are an important part of a cost analysis. The relationships between costs, individual performance, and system performance are complex.

The following guidelines are pertinent to the data to be assembled and calculations to be performed in the cost and performance analysis:

- Cost data will be assembled on a consistent basis.

- Calculations will be performed according to established and reproducible methods.

- Consistent sets of assumptions will be used across technologies.

\section{Issue Description}

The cost and performance issues discussed in this section are classed as elther direct or indirect. Direct costs primarily concern the technology, and indirect costs concern such aspects as the impact of energy costs on electrical consumption or the dislocation costs of shutting down facilities of decreasing viability due to the strong entry of the SPS into the commercial market.

The four main issues concerning energy technology costs are as follows:

1. Value of a Technology. The value of an energy technology is determined by taking the difference between the cost of generating electricity with the new technology and the cost of generating electricity without the new 
technology. Thus, value may be interpreted as the upper bound estimate of the price an electric utility would be willing to pay for a new energy technology. The calculation is carried out as follows (Fig. 3.2):

- First, a reference electrical system is expanded using a new energy technology whose costs are not well-known but whose operating characteristics (size, reliability, maintainability) can be adequately described. The overall system cost (costs for the technologies within the system) and performance are determined.

- Second, a conventional technology, whose costs (e.g., capital costs and fuel costs) and operating characteristics are well-known, is assumed, and the reference system is expanded so that it reasonably approximates the system performance calculated for the new technology in the first step.

- Third, the difference in overall system cost between the two steps provides an upper-bound estimate of value of the new technology.

2. Ownership Mode. What are the cost impacts of SPS ownership modes on groups within our social structure? Economic impacts will mainly be considered in terms of taxes and financial risks (i.e., capital cost for private ownership).

CHARACTERIZATION CALCULATIONS $\quad$ ANALYSIS

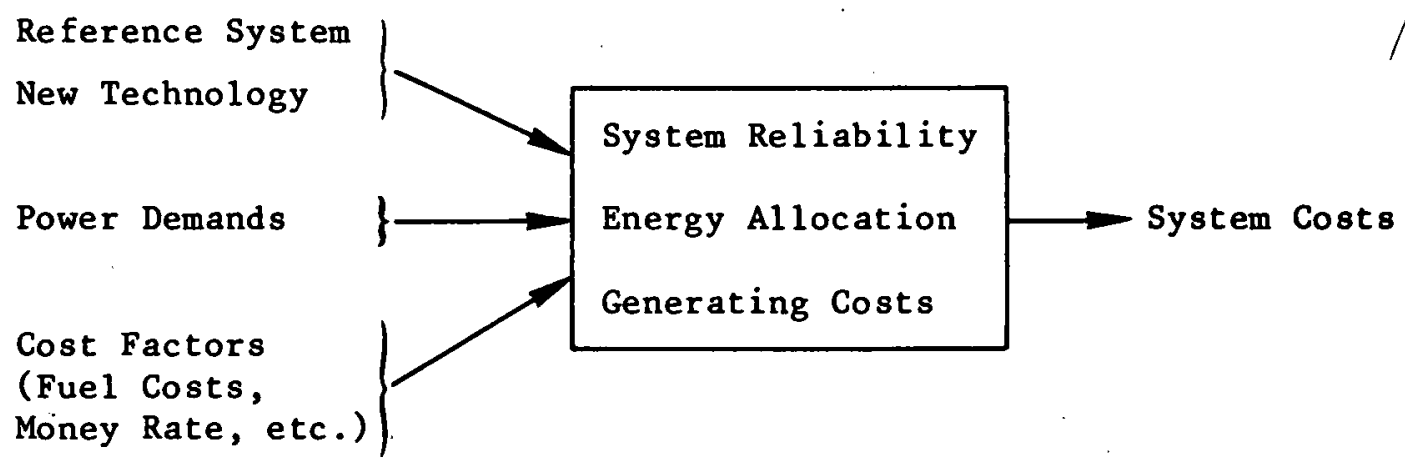

Fig. 3.2 Flowchart for Cost and Value Calculation 
3. R\&D Costs. What are the costs of future research and development for SPS and selected alternative technologles? If these, costs were arbitrarily charged to electrical generation over a plant construction interval, e.g., 30 years, would they significantly reduce the value of the technology to utilities?

4. Cost Uncertainties. What are the cost uncertainties? How can they be incorporated into the analysis in a meaningful and helpful manner? The goal is to produce bounds on cost estimates and to identify critical cost factors.

The following are the two main issues concerning performance of alternative rechnologles:

1. System Performance. What are the impacts of adding many units of a specific technology to utility systems on the mix of generation plant types, fuel requirements, and general utility operation?

2. Location and Technology Application. What are the regional var1ables of deployment of the various technologies, e.g., siting requirements, location of fuel or heat sources, and transmission distances?

\section{Units of Measure}

The unit of measure most frequently used in evaluating cost issues is the cost of electricity, expressed in mills/kWh. This unit is used because the product (energy) is measured on a unit cost basis by the consumer, who sees the monthly or bimonthly bill in dollars but views specific electricity costs in terms of cents/kWh. In some instances, the electric bill shows a demand charge in terms of dollars per kilowatt plus an energy charge per kilowatt hour. For these reasons, analysis of electricity costs for the various technologies will focus on the mills/kWh at the busbar of the generating plant. Transmission costs will be included where applicable on an incremental basis, i.e., the added transmission cost that may clearly be assigned to a technology because of such factors as increased distance of the facility from the load center or the need for special transmission lines. All four cost issues (value of a technology, SPS ownership mode, R\&D costs, and cost uncertainties) will mainly be analyzed in mills/kWh. In addition, the R\&D costs (1.e., future costs related to research and development of energy technology elements) will be expressed in terms of the dollar expenditures 
needed to develop the technology. Of major concern in the area of cost uncertainties is the capital cost of the energy facility, which is usually expressed in dollars per kilowatt. Table 3.1 summarizes. the units of measure for the cost 1ssues.

The measurements involving technology performance will be expressed largely in relative terms because this activity will be, for the most part, qualitative in nature. For those comparative measurements that can be expressed in physical units or with an indicative parameter (e.g., forced outage rate), numerical quantification will be used.

Methods

The central analysis will be the estimation of the value of a technology to electrical energy generation systems after 2000. This involves the use of reference utility generating systems ${ }^{33}$ and expansion of these using improved current technologies. Expansions of the reference utility system can then be made using the alternative energy technologies.

Calculations will be made under a number of conditions that involve coal and uranium prices, real escalation of capital goods costs and labor costs, and electrical power growth rates. In addition, a few evaluations of

Table 3.1 Unito of Mcaourc for Coot Analycic

\begin{tabular}{|c|c|c|}
\hline & Issue & Units \\
\hline & Value of Technolngy & $\dot{M i} 11 \mathrm{k} / \mathrm{kWh}$ and $s / \mathrm{kW}$ \\
\hline 2. & Ownership Mode & Mills $/ \mathrm{kWh}$ and $\$ / \mathrm{kW}$ \\
\hline 3. & $R \& D$ Costs & Mills/kWh and dollars \\
\hline & Capital Costs & Mills/kWh and dollars \\
\hline & Cost Uncertainties & $\begin{array}{l}\text { Mills } / \mathrm{kWh} \text {, or probability distributions } \\
\text { of mills } / \mathrm{kWh} \text {; also dollars/kW if sultable }\end{array}$ \\
\hline & System Performance & $\begin{array}{l}\text { Quantitative or qualitative description of } \\
\text { impacts depending on performance parameter }\end{array}$ \\
\hline & $\begin{array}{l}\text { Location and Technology } \\
\text { Application }\end{array}$ & $\begin{array}{l}\text { Energy source avallability by region (DOE } \\
\text { electrical energy regions or reliability } \\
\text { council) and potential transmission costs } \\
\text { in mills/kWh }\end{array}$ \\
\hline 8. & Operation and MaIntenance & $\operatorname{Mi11s/kWh}$ \\
\hline 9. & Decommissioning Cost & Dollars \\
\hline
\end{tabular}


alternative future scenarios involving other parameter changes will be made. On the whole, a large number of cases need to be studied with system expansion periods of 10 to 30 years for each case. To construct these analyses efficlently will require the use of an appropriate computational tool, that is, a utility expansion model.

There a number of such models* available, 34 and the following criteria for model selection will. be used: low computer costs, availability, nonproprietary nature, and internal consistency. Low computer costs and nonproprietary nature are particularly important to assure that results of the SPS comparative assessment can be reproduced, checked, and challenged (if need be) by researchers outside the SPS-CDEP program.

Most of the numerous computational models for cost analyses of individual electrical generating technologies employ straightforward procedures for calculating engineering cost. In cooperation with the Department of Energy [then the Energy Research and Development Administration (ERDA)] and the Electric Power Research Institute (EPRI), the MITRE Corporation sponsored a workshop on engineering economic analysis of advanced technologies and reviewed many analytical approaches and their implications. 35 An approach that uses the revenue requirement calculations for economic comparison of alternatives is described in the EPRI Technical Assessment Guide.36 Prelimliminary calculations have been performed using this approach, and these indicate the applicability. and ease of use of this well-documented method.

The issues of cost impacts of ownership mode, R\&D costs, and cost uncertainties will be studied with simpler analytical techniques that use a single technology and employ cost-levelizing procedures (i.e., equivalent annual costs). Some of these estimates will include a parametric variation approach. In all, a large number of simple calculations will be required.

Analysis of "system performance" issues will be accomplished mainly through a discussion for each technology characterized. Issues involved in location and technology application will be analyzed in the same format

\footnotetext{
*e.g., the General Electric Optimized Generation Planning (OGP) program, the Westinghouse Capacity Expansion Program, the Wien Automatic System Planning (WASP) Code, and the Argonne National Laboratory Electrical Utility Generating System Analysis Code (SYSREL).
} 
for each technology. These evaluations will be both qualitative and quantitative in nature.

\section{Data Bases}

A guideline of this assessment is that the data required should be readily avallable to groups that may wish to make their own analyses. This cannot be completely guaranteed, but proprietary data cannot be used because the traceability requirement that is standard for public assessments would be jeopardized. One of the first activities is to identify the recent literature containing cost and performance data. Tables 3.2 and 3.3 contain some nominal input data and some assumptions, respectively, from a methodology report on solar-thermal power plant studies. 37 These examples are typical of the input required for the SPS study.

In order to promote uniformity in their evaluations, EPRI has issued a technical assessment guide, 36 that will serve as a source of data where applicable. The data are both national and regional in character.

MITRE has. prepared a nine-volume collection of systems descriptions and engineering $\operatorname{costs}^{7}$ for the Division of Solar Energy in.DOE. These data support the SPURR model (System for Projecting Utilization of Renewable Energy Resources) and w1ll form part of the data base for the SPS assessment.

\subsection{ENVIRONMENTAL IMPACTS}

\subsubsection{Health and Safety Effects}

The objective of this analysis is to assess the extent of known and potential public and occupational health and safety impacts due to the SPS and alternative energy technologies.

Issue Description

It is generally accepted that the relative impact on human health and safety is among the most important considerations in a comparative evaluation of alternative technologies. The general acceptance of high priority for health and safety issues does not imply, however, that quantification of such effects will result in common values for straightforward ranking of systems 
Table 3.2 Nominal Values in Cost Analysis

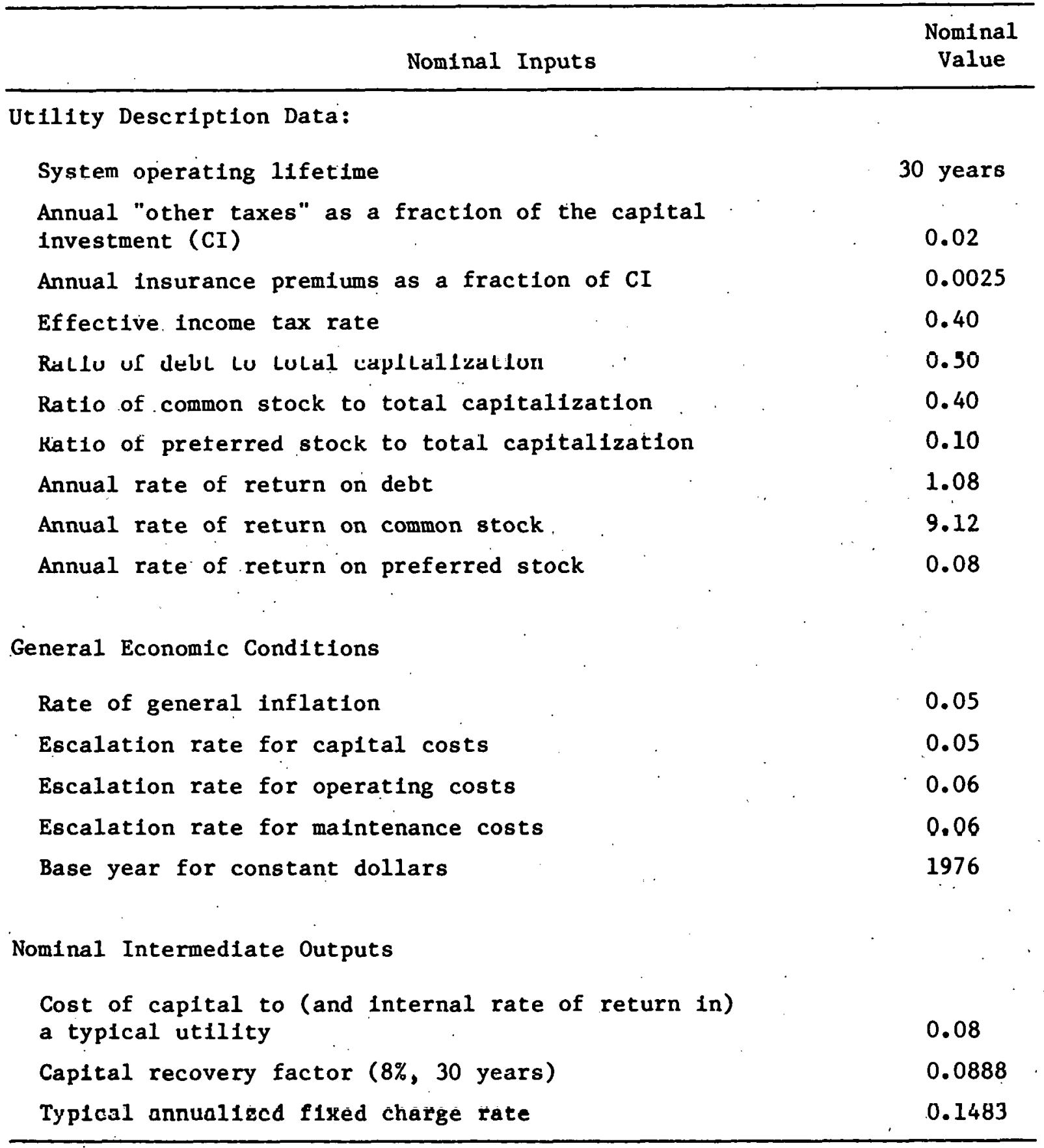

Source: Ref. 37. 
Table 3.3 Economic Work Sheet

Assumptions

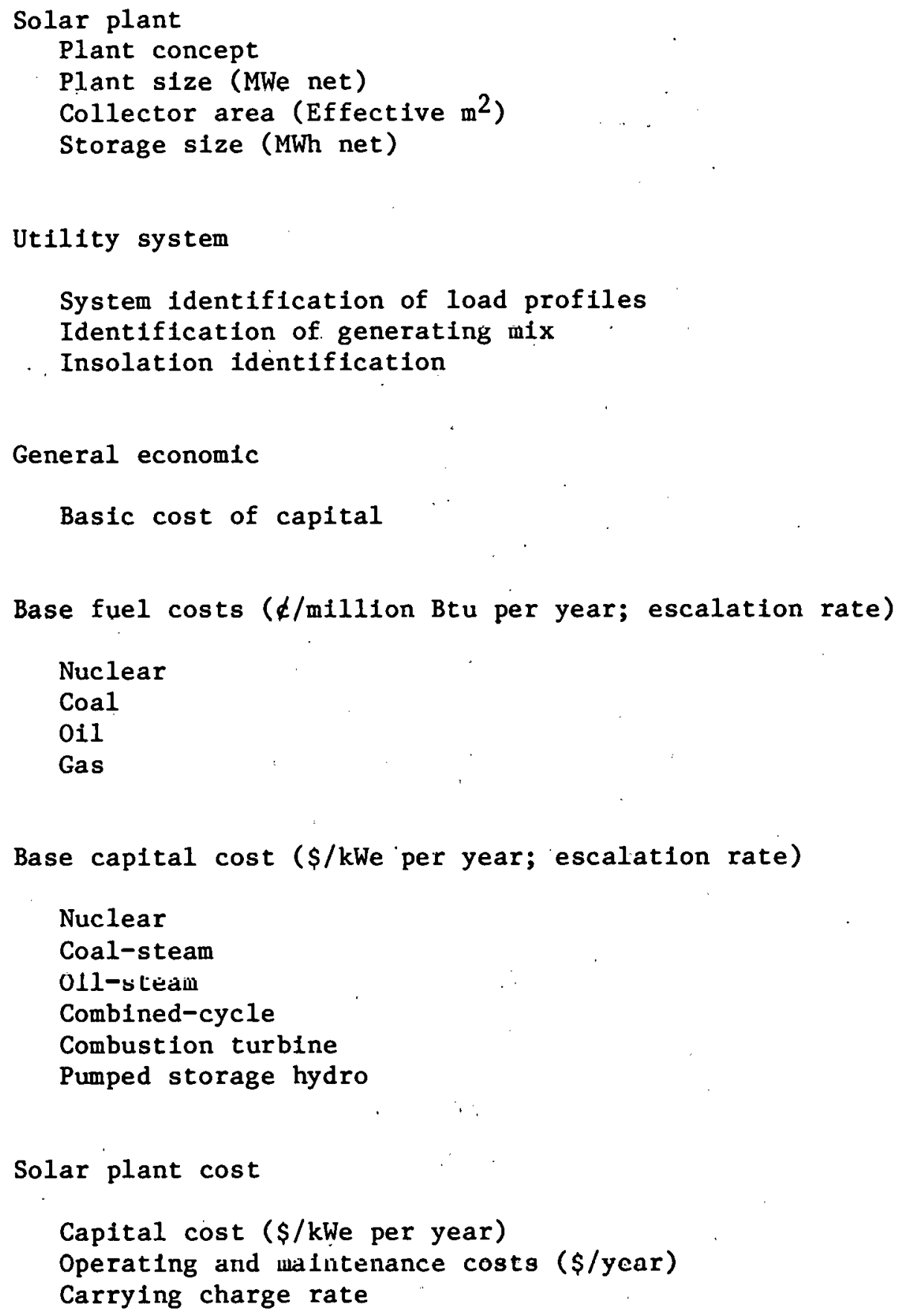

General economic

Basic cost of capital

Base fuel costs ( $\$ /$ million Btu per year; escalation rate) Nuclear

Coal

Oil

Gas

Base capital cost ( $\$ / \mathrm{kWe}$ per year; escalation rate)

Nuclear

Coal-steam

Oll-steam

Combined-cycle

Combustion turbine

Pumped storage hydro

Solar plant cost

Capital cost ( $\$ /$ kWe per year)

Operating and waintenance costg ( $\$$ /year)

Carrying charge rate

Source: Ref. 37. 
because energy systems differ not only in the level, but also in the manner in which health and safety effects are incurred. These differences affect society's perceptions of "acceptable" health and safety impacts and thus should be preserved in the analysis. Following are short descriptions of differences to be included to the extent possible with available analytical tools.

The first aspect in which energy systems differ with regard to health and safety issues is impact severity. There are a number of quantitative measures of the severity of accidents and disease. One straightforward approach, which will be used here, is to estimate the number of deaths incurred and the number of person-days lost. Nonfatal events span a range of health impacts from nominal to permanently disabling, with a corresponding iduge of cose 1mpacts, both emotional and financial. These differing effects can be combined into single units of measure such as person-days-lost (PDL) if productivity is the factor under consideration. Where practical, other factors such as emotional impact and public perception of the impact severity will also be considered.

Energy systems also differ in whether they affect occupational populations or general populations or both and in the levels of such imparts. Occupational health effects from energy technologies are generally characterized by high risk to small populations, whereas public health effects are generally characterized by risks that are low but affect large pnpuletions. Therefore, separate categories will be maintained for public and occupational health impacts.

Impacts due to accidents and disease will also be conoidered. Accidents involve immediate cause-effect relatinnships and aro generally per. ceived as avoidable. As a result, mitigation procedures to prevent accidents are relatively straightforward, although possibly expensive. Causeeffect relationships for disease are much less visible and not as immediate. Latent periods between exposure and response may span years and mask the original cause. In addition, the range of individual responses to accidents is relatively small compared to that for disease--there may be significant differences among individual responses to similar exposures.

$$
\text { W. - Womontinn of hoalth effects and the ability of society }
$$


the effects occur in one event or are spread out over a period of time, i.e., whether they are catastrophic or noncatastrophic. The high visibility and potential magnitude of catastrophic events increase both public awareness and the short-term costs of dealing with the effects of such events. Catastrophic events also overload the capacities of available health systems. Health effects from noncatastrophic events are more easily accepted because of their chronic nature.

Closely related to the last consideration are immediate and delayed effects. Immediate health and safety effects require immediate action (e.g., hospitalization and medical care) and, as such, are more visible and more accurately reported than are delayed effects. Delayed effects such as cancer or mutation are often "lost" due to the lack of visible cause-effect relationships, migrating populations, and reporting errors. The costs of immediate effects must be dealt with immediately whereas the costs of delayed effects may be considered to diminish the value of future societal contributions by impeded energy development and the necessity for developing mitigating procedures. As a result, immediate health risks are perceived differently from delayed health risks by both the general public and policy makers. Thus, the assessment of the two types of risks will remain separate.

\section{Units of Measure}

Public and occupational impacts on health and safety will be compiled according to the units of measure listed in Table 3.4. Within each of the categories in that table (accidents, disease, catastrophic events), the units of measure begin with qualitative descriptors (e.g., accident hazard description) and proceed through progressively more quantitative evaluation measures (e.g., percent of accident occurrences resulting in person-days lost greater than some $\mathrm{x}$ ). This format not only allows detailed compilation of impact estimates for energy systems such as conventional coal and nuclear systems, for which more precise quantification is possible, but also provides for preliminary comparison with advanced technologies, for which, in many instances, information is currently limited to the qualitative identification of potential risks or hazards.

The categories in Table 3.4 will be used for each energy production system and also for each of the major phases of each system (e.g., raw 
Table 3.4 Qualitative Indicators and Units of Measure of Public and Occupational Health and Safety Impacts per Unit Output

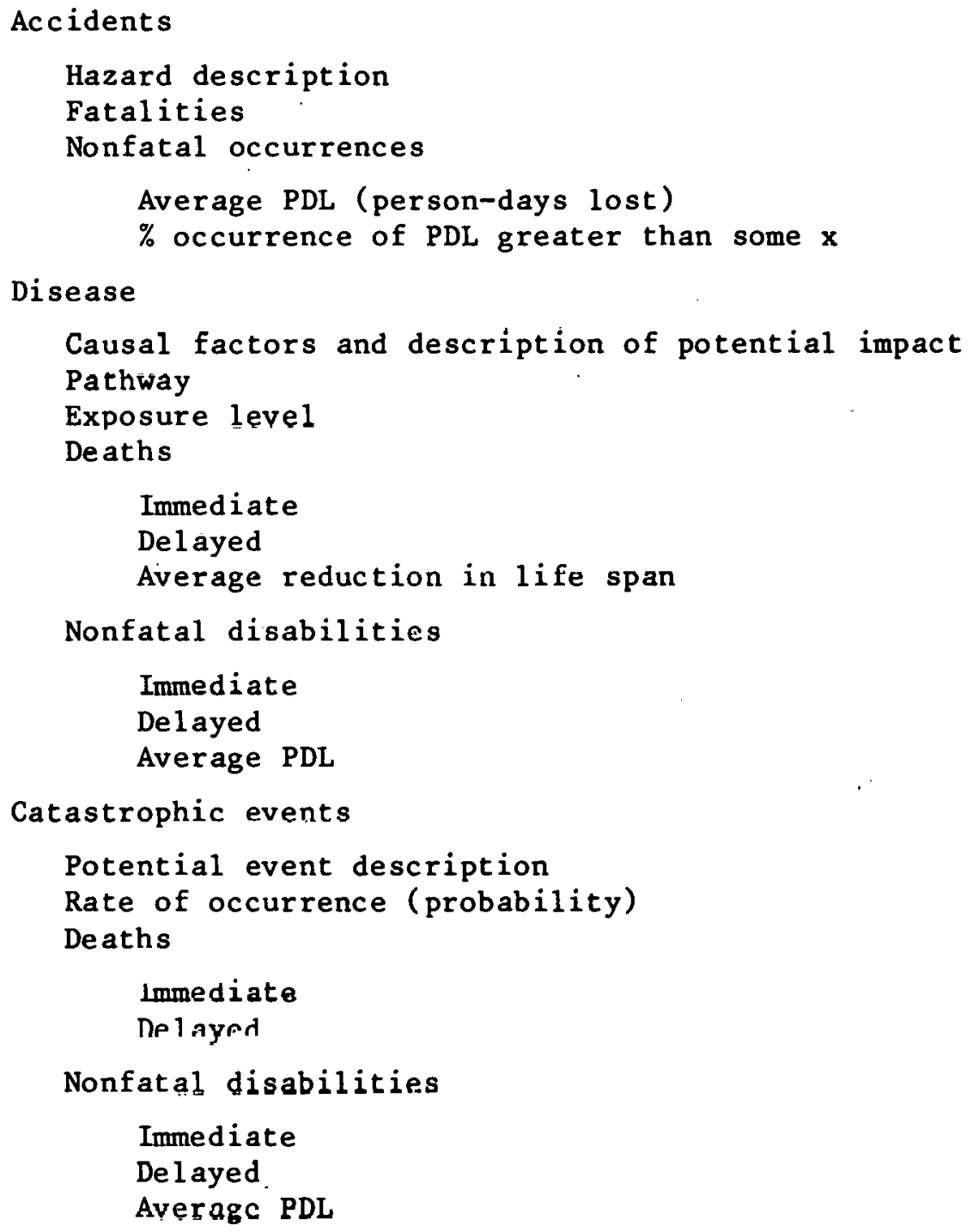

Causal factors and description of potential impact Pathway

Exposure level

Deaths

Immediate

Delayed

Average reduction in 1 ife span

Nonfatal disabilities

Immed iate

Delayed

Average PDL

Catastrophic events

Potential event description

Rate of occurrence (probability)

Deaths

Immediate

Me 1 ayed

Nonfatal disabilities

Immediate

Delayed

Averagc PDL

Total PDL 
material extraction, material processing), described in the following methods subsection. The quantitative units of measure will be based on some unit of output energy (e.g., per MWe). Since many health and safety effects cannot be precisely estimated with current knowledge, it is important that where quantitative estimates are included, an estimate of the uncertainties should also be given so that premature technology comparisons are avoided and areas for further study are identified.

Methods

The basic study approach (see Table 3.5) is to initially provide, within the consistent framework described in the preceding subsection, largely qualitative descriptions of the significant health and safety issues for each of the broad categories of energy alternatives to be considered. Where readily availablé, these issue descriptions will be supported by quantitative information; however, the initial issue description will precede the full development of technology characterizations and will thus be 1 imited in the degree of quantification possible. Included as part of the issue identification will be 1 istings of potential toxic or carcinogenic components within the process streams and effluents; descriptions of potential impact pathways; pollutant toxicity levels and dose responses, if known; industrial sectors supporting the energy technology; the nature of occupational hazards within those sectors; and feasible scenarios for occurrence of catastrophic events.

The preliminary issue identification of the health and safety assessment will be an important source of information for defining the methodology for more quantitative evaluations that will utilize more detailed characterizations of the energy systems and options. The quantification in the second step of the health and safety assessment will be utilized in side-byside comparisons of generic unit systems. The final steps in the comparative evaluation will consider the influence of variations in geographic distribution and level of deployment in the alternative futures analysis and evaluate the cost and effectiveness of strategies for mitigating the health and safety impacts of the alternative technologies.

For purposes of uniformity and consistency in the comparative evaluation, the health and safety issue identification for each energy production system will be compiled separately for each of the following components of the 
Table 3.5 Components of the Comparative Assessment of Health and Safety Impacts

Step I - Issue Identification

Preliminary Energy System Definitions (Qualitative)

$\quad$ System
Coal
Nuclear
Geothermal
Solar Terrestrial
SPS

Fuel Cycle

Raw Material Extraction

Material Processing

Fabrication

Transportation

Construction

Operation and Maintenance

Waste Disposal and Deactivation

Identify Health and Safety Issues (Qualitative and Quantitative Where Readily Available)

Toxic and Carcinogenic Process Components and Residuals

Exposure and Impact Pathways

Exposure Effects

Accident Hazards

Description of Potential Catastrophic Events

Probability of Catastrophic Event

Step II - Side-by-Side Comparative Assessment

Detailed Energy System Definitions (Quantitative, from External Study)

Deaths, Person-Days Lost (See Units of Measure, Table 3.4)

Level of Uncertainty

Identification of Data Gaps and Research Needs

Step III - Alternative Futures Comparative Assessment

Alternative Futures Definition (from External Study)

Level of Technology Deployment

Geographical Distribution

Alternative Futures Health and Safety Impact Severity

Cumulative Effects

Reglonal Differences

Step IV - Impact Mitigation Assessment

Options for Health and Safety Impact Mitigation

Cost

Effectiveness 
fuel cycle: raw material extraction; material processing, fabrication, and transportation; construction; operation and maintenance (O\&M); waste disposal; and deactivation.

Health and safety impacts due to raw material extraction, including mining for fuels such as coal and uranium as well as for component materials such as tron, copper, and bauxite, will be evaluated. Also included is extraction of materials indirectly used in the component construction (e.g., coal used for steel production). The primary impacts on occupational populations will result from the safety uncertainties inherent in extraction activities, although exposure to health stresses such as coal dust will also be important.

Material processing includes coal and nuclear fuel processing, and production of components such as steel, aluminum, copper, cement, and lumber necessary for fabrication of energy technology structures and process machinery. Occupational impacts include exposure to stresses such as metal fumes, heat, dust and noise, as well as unsafe working conditions. Public health risks include exposure to atmospheric, aquatic, and solid waste emissions.

Health and safety aspects of the production of steam generators, photovoltaic cells, copper tubing, and other process components necessary for each technology will also be considered. Occupational, risks will include exposure to machinery such as stamping presses and chemical stresses such as exposure to gallium aluminum arsenide.

Also included will be the transportation of fuels, processed materials, fabricated components, and wastes, from the point at which they are produced to the point at which they will be utilized or disposed of.

The construction phase of the energy cycle includes assembly of components at the facility site. Carpenters, plumbers, electricians, and steel and concrete workers assembling the plant will be exposed to major health and safety risks. The transportation of needed raw materials and process components will result in additional occupational and public health impacts.

Routine O\&M procedures will result in occupational health and safety impacts. on plant personnel. The magnitude of effects will vary with technology. Potentially significant public health impacts may result from environmental emissiuns from process waste streams. 
The health and safety impacts of handling and disposal of waste materlals from energy facilities will differ significantly with each technology. For example, the occupational and public impacts of disposal of nuclear wastes or carcinogens from coal gasification processes will be different from those due to disposal of photovolatic cells from centralized solar facilities. The category of impact resulting from the latter situation will include disassembly and disposal or recycling of the decommissioned facilities.

Depending on the nature of the health and safety risks, various techniques will be used for estimation; however, generic approaches will be defined for the following impacts:

- nccupational accidents and disease

- Effects of air pollutant inhalation

- Radiation effects

- Transportation effects

- Catastrophic occurrences

The approaches for estimating each of the listed impacts will be addressed in the following paragraphs. For each component activity of the fuel cycle, the person-hour labor requirements will be established on the basts of national productivity and employment statistics. Data on accidents and disease in the industry will then be utilized to determine their rates of occurrence in the energy-related activity. These data can be obtained from both state and federal sources as well as industrial reports. A primary source of such information is the National Bureau of Labor Statistics, which routinely gathers and disseminates occupational accident data.

Fxisting emiceion rates or emission rates subject to anticipated state or federal standards are utilized to determine air pollutant exposure for a generic population. Dose response functions have been adopted from the work of S. Morris 38 of Brookhaven National Laboratory and will be fitted to a generalized cigarette consumption model.

Radiation releases from all segments of the nuclear fuel cycle are well documented in the open literature (see bibliography for some key references). These emissions can be used to estimate the population dose from the cycle. The health effects from low-level radiation can be quantified in terms of radiation-induced cancer mortality. Such an analysis would include the relative risks of developing specific tumors. 
For each phase of each energy technology assessment, the tons of material requiring transportation, the travel mode, and the number of miles transported will be developed on the basis of process needs and locational estimates. These factors will be used in conjunction with train, truck, barge, and pipeline occupational risk statistics, number and severity of gradecrossing accidents, and other related public health data to determine health and safety risks associated with each energy technology. In the case of SPS, a unique and important area of interest and concern is that surrounding the transport of materials to GEO, including the risks of rocket launchings.

Catastrophic occurrences are primarily related to potential accidents in the nuclear fuel cycle and have been evaluated in detail (Rasmussen report).39 Such occurrences in other technologies are feasible but have not been quantified in similar detail. Preliminary estimates of the likelihood and the magnitude of possible catastrophes will be made through analogy with documented man-made and natural disasters.

\section{Data Bases}

As discussed in this section, the basic study strategy is to compile results of previous energy-related health and safety studies into a preliminary comparative framework. Key references and data bases to be critically reviewed and utilized are listed in the bibliography. This listing does not include anticlpaced input through discussions with participants of previous or ongoing health and safety studies, which may be particularly significant for Identifying the effects of developing technologies.

\subsubsection{Welfare Effects}

Several types of environmental degradation effects are not directly related to public or occupational health and safety. For the purposes of this methodology, these effects will be referred to as environmental welfare effects, since they concern the well-being of individuals. Included in this group are effects such as materials corrosion, deterioration of aesthetic quality, removal of bodies of water or land from desired uses, and crop damage. The welfare effects associated with an SPS system include radio frequency Interference, communications disruption, interference with electromagnetic equipment (e.g. electronics, computers, electro-optics), and land use 
disturbances. Specifically excluded from this category are effects on health and safety, natural biological systems, resource depletion (including direct land and water use), and social and economic dislocations. Conditions following accidents were also not included in this study.

At issue in the SPS comparative assessment is how the welfare impacts associated with SPS deployment compare with those of other energy supply systems. However, further analysis is required to identify which of the impacts are the most important in the determination of welfare effects.

Determination of the environmental welfare effects of each energy technology begins with an examination of the various activities involved in the fuel cycle beginning with extraction of the resource and extending through the production of electricity and decommissioning. These activities result in environmental impacts such as noise and air and water emissions. In turn, the environmental impacts could result in welfare effects such as property damage, climatic change, interference with other activities, and aesthetic disturbances. Fig. 3.3 shows this activity-impact-effect chain used for categorizing the environmental impacts and welfare effects of the various activities in the fuel cycle.

Units of Measure

Since the welfare impacts span a wide range of conditions, there is no single metric that can be used to quantify the extent of the effects. In some instances (e.g. deterioration of aesthetic quality) it is not possible to quantify the effect at all. The comparative assessment will, therefore, employ a number of measurement units to address the issues. For those impacts that can be readily measured by economic costs, the metric will be the dollar value of the impact (e.g., cost of retrofit of electronic equipment to eliminate interference, cost of providing additional noise insulation). Other impacts (e.g., land use disturbance) w1ll be wedsured by the number of persons affected. Qualitative evaluations of the extent of impacts (e.g., severe aesthetic degradation) will also be made. Other metrics will be developed as appropriale. 


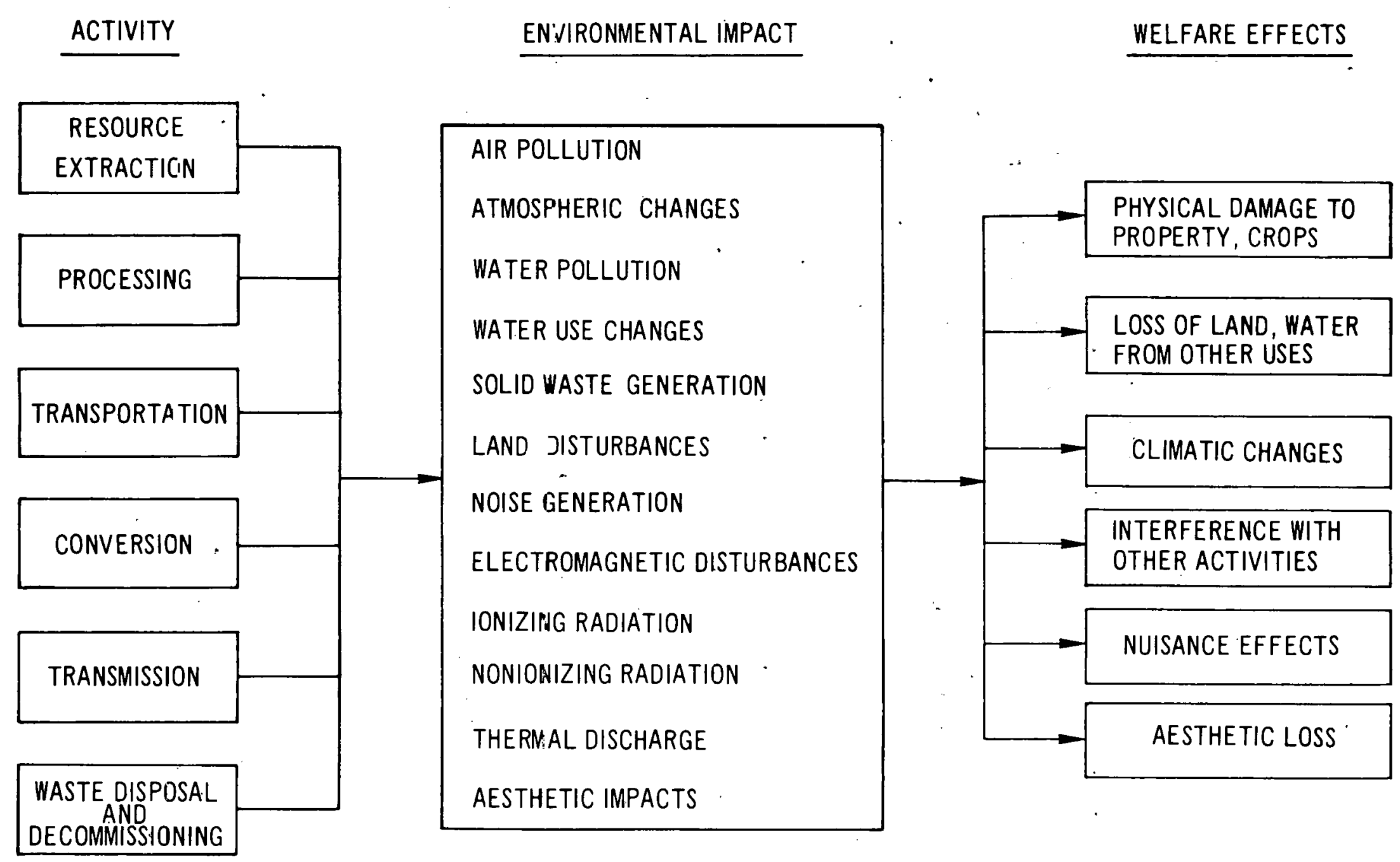

Fig. 3.3 Pathway of Energy Activities, Impacts, and Welfare Effects 
$\underline{\text { Methods }}$

The analysis will begin with a systematic identification of the welfare impacts of the various energy supply technologies. Impacts will be identified for the entire fuel cycle.

Next, a set of metrics will be selected for estimating the extent of the effects. Where appropriate, the metrics will be grouped for the purpose of direct comparisons between technologies. For example, the number of persons affected by the appropriation of land for the energy supply system can be a metric common to all of the technology systems. Some of the economic costs can be compared directly whereas others must remain distinct (e.g., the cost of rotrofitting personal televislun sets to eliminate interference must be borne by the individual consumer, as opposed to the cost of crops damaged by air pollution). The process of selecting and grouping the metrics will determine the types of comparisons that can he made.

The quantification, where appropriate, of the extent of the impacts is the next step. An important point to emphasize is that no attempt will be made to reduce all of the impacts to a common metric such as cost. Many previous efforts at doing this have resulted in extended controversies over assigning weighting values to diverse impacts, since there is no consensus about the proper way to compute the common metric. The analysis will therefore preserve the diverse metrics for evaluation.

Synthesis of the resulto into a comparison of the cechnologies will be the final step, Conclusions will be drawn for those metrics that are common to all the systems, and a qualitative evaluation of the other issues will be made.

Data Bases

A literature review will be used to assemble information on conventional energy system (e.g., coal, nuclear) impacts. The data for nonconventional systems (e.g., terrestrial. solar) will be estimated using conceptual system definitions. Sources of information on SPS will be the environmental and societal assessments of the CDEP, both of which will be generating data useful to this analysis. 


\subsection{RESOURCES}

For the comparative evaluation of resource consumption by SPS and alternative technologies, five resource categories have been selected: land, critical materials, energy, water, and labor. A more in-depth analysis will investigate the cumulative effects of the technologies in different scenarios.

\subsubsection{Land Use}

The objective of the land category is to characterize the nature, purpose, and effects of land used by an energy technology. Criteria used to characterize land use include: area, time (temporary versus permanent), and lost opportunity (recreation, preserves, agriculture).

\section{Issue Description}

In comparing energy alternatives, one of the critical resources that must be evaluated is land. The first and most obvious issue that must be addressed is simply the amount of land that a given technology will require. Second, the length of time the land will be required:must also be determined. For some technologies, the area required will vary throughout the plant's life cycle. For example, different amounts of land may be required during the plant's construction, operation, and after shutdown (such as for storage of nuclear waste).

Also of interest is the location of the required land. The location w11l have a bearing on direct cost and social costs. The direct cost (e.g., \$/acre) will obviously vary with location. In addition, the location may. affect other land requirements, such as the amount of right-of-way needed for transmission lines. Social costs w11 depend on the proximfty of land to other public functions, such as housing or recreation. The denial of opportunity to use the land in some other way is a social cost. Initial evaluations will be performed on a regional basis, avoiding the complexities of analyzing specific sites.

\section{Units of Measure}

The primary unit of measure is simply land area. For a side-by-side analysis, the area will be normalized on per plant or per unit energy output. The land area required may also be broken down into the phases of life cycle 
and function, e.g., mining, construction, the plant itself, transmission, and waste disposal. The length of time of use is also a unit of measure pertaining to each of these categories. Direct and social costs will be incorporated only insofar as they are evident or encountered in other studies.

Methods

Most of the available comparative assessments of land requirements take a simple side-by-side approach. In this approach, the land area required by each technology is simply stated, typically normalized per unit of energy output. The data may also be broken down accurding to the purpose and duration for whlili the land ic used, littile artenllum is glven to dirert nr social costs.

Limitations on the availability of data suggest that the present assessment should also take a side-by-side approach. The approach will mainly entall compilation of the data already available from sources cited in the reference section. These sources present adequate measures of the amount, time, and manner of use of land required for given plant designs. In cases where it is possible to surmise the type of land that would be used, as will be the case for regional sites, greater detail will result.

\section{Data Bases}

Several side-by-side assessments give useful data. Among these are Caputo's initial comparative assessment, 5 Gallagher's 40 "Energy Supply Planning Model," and the "MERES" system of the Council on Environmental Quality.41 A MITRE/METREK study ${ }^{7}$ of solar-related technologies also identifies likely locations by census region and mentions environmental or economic facturs resulting in cost variation among regions. A land use anaiysis fur 3P3 lids been prepared by Allan D. Kotin Economic Consultants.42 If not explicitly stated, the land area required for fuel mining can be traced back throngh data on the amount of fuel required.

\subsubsection{Critical Materials}

The assessment of critical materials resources concerns material demands, current and required production rates, dependence on foreign supplies, and supply-demand consequences for sPS and each of the alternative technologies. 
Issue Description.

The evaluation of critical materials is important primarily for economic reasons: The possibility exists that a technology could be constrained because a necessary material is unavailable at any price. However, such a constraint does not seem to apply to any of the presently considered technologies. The main concerns seem to be in the following areas:

1. Domestic production capacity. What is the current capacity? What is its normal rate of growth? What rate of growth would be needed to meet a given demand?

2. Foreign dependence. If domestic supplies of a material are inadequate, where will the balance come from? How will it affect the U.S. balance of trade? Are there possibilities of cartels?

3. Price of materials. The price is directly related to the status and form of material resources. For example, how much of the resource is already in proven reserves rather than in probable or subeconomic reserves? Are the resources in forms that require different production methods, for example, gallium may be processed from bauxite or from clays.

4. Cost of Lost Opportunity. If a material is used for an energy technology, what other possible uses of the resource will have to be foregone?

The importance of these issues should not be overlooked. The requirement of a high production growth rate in a material processing industry could be difficult to meet, but even if that is not the case, there is a need for advance knowledge so that industry will have time to gear up for the demand. If high import levels are required, there may be uncertainty about prices and availability of materials. The effect of an energy technology on materials prices will, of course, not be confined to the energy industry; but will affect the whole economy. Although the cost of lost opportunity is an important issue, it is more difficult to evaluate, since it is difficult to speculate on the possible alternative uses a material may have in the next few decades.

Units of Measure

The obvious unit of measure for a critical materials study is the amount of a material required by a technology. For comparison of different 
technologies, the material quantities would typically be normalized, such as per unit of power or energy output. Such units are typical of system characterization comparisons. However, to move beyond such an assessment approach, it is necessary to consider the material quantities in comparison with other factors, such as:

1. Current production capacity, and the projected ability to increase it.

2. The resource base, broken down by categories of economic feasibility, geological assurance, and form.

3. The resource base, broken down by geographical 1ocation.

4. Price of the material, related to factors 2 and 3 above.

Data for all of these factors is generally available from the Bureau of Mines 43 or the U.S. Geological Survey.44 The quality of the data varies, however. Some resource assessments are more certain than others, and the uncertainty is especially great in the factors requiring the most projection, such as undiscovered resources, or the ability of industry to expand production capacity. Still, the availability of some data makes all of the above units of measure feasible: For the initial comparative assessment, however, only a subset of the complete detalled breakdown of units suggested by the factors above will be necessary. A good idea of what issues require further exploration can be learned from a small number of simple units, such as:

1. Material: quantity required versus current produrtion capacity.

2. Quantity required versus proven reserves, or versus total resources.

3. Quantity required versus percentage of the resource that is imported.

4. Price of the matertal as related to proven reserves or total resources.

Methods

The simplest comparative assessment of critical materials consists of a side-by-side statement of system characterizations. That is, the amounts of various materials required by a reference design are stated but with no assessment of their criticality. Methods that go beyond this approach use some screening process to identify critical or potentially critical materials. 
One very simple screen checks off the list of materials against an outside source's list of critical materials but without regard to the quantities being considered. More thoughtful screening methods establish criteria related to the supply/demand balance. Possible problems indicated by the screens are explored further manually. The screening may be comparatively simple and done manually, or very detailed, making good use of a computer for bookkeeping. The methodology developed at Pacific Northwest Laboratory 45 is of the latter type.

From the available data, system characterizations of the technologies under consideration may be obtained. However, except for SPS and photovoltaics, little has been done to assess the criticality of the required materials. For SPS and photovoltaics, compilation of existing data will suffice. However, for most of the technologies a manual screening method will be employed, followed by further manual investigation of possible materials problems. The screening criteria will be related to the units of measure noted earlier, with levels set at which to flag potential problems. For example, a material would be flagged if its demand represents more than a stated percentage of current production. If flagged, the issue would be investigated further to see if there really is a problem or if there are mitigating factors.

Data Basee

Several earlier comparative assessments contain useful system characterization data. These studies include Caputo's initial comparative assessment. 5 Gallagher'e "Energy 3upply Planning Model",40 and MITRE/METREK's System Descriptions and Enginesring Costs for Solar-Related Technologies.? Additional characterization data are available from studies of individual technologies. Two studies also assess criticality: the PNL study mentioned earlier; 45 and a study of SPS by Allan D. Kotin Economic Consultant.s.42 In addition, Battelle Columbus is analyzing the potential criticality of terrestrial a1 ternativee.

Data about the resource base and importation of materials is generally available from the Bureau of Mines 43 and U.S. Geological Survey.44 Data compiled in. other references may. be generally traced back to these sources. 


\subsubsection{Energy Balance}

An analysis of "net energy balance" is designed to.determine the quantity of energy that must be invested in building and operating an energy supply system and to determine if that system is capable of returning enough usable energy to justify the investment. The concern for net energy return on investment for an SPS system lies in the significant amount of energy that must be expended in installing a series of power satellites in geosynchronous orbit; several other systems are also highly energy intensive.

\section{Issue Description}

The issues of cuncern in conducting a net energy analysis as part of the comparative assessment are the following:

1. For each of the electricity generating technologies considered, how much energy (in the form of electricity, fuels, and materials) must be expended to build and operate the system?

2. For each technology, how efficiently does it utilize the primary energy resource? Special emphasis must be given to the use of nonrenewable resources.

3. For each technology, what is the "payback period"? That is, how long will it take for the system to generate a quantity of energy equal to the energy investment?

4. Does the net energy analysis indicate that the potential return on investment for an SPS system is sufficient to warrant continued development, $u r$ is the rate of return thn low to risk the investment? This must be answered in the context of a comparison with alternative iechinulugies.

It must be emphaslized that net cnergy alialyais cannot provide the definitive answer to the problem of selecting a technological alternative. It can only provide another piece of information upon which to base a decision. All four of the above issues are important in answering the net energy balance question; however, because of limitations of the methodology and data, not all of them can be answered completely or definitively.

The one major question that will not be adtressed in this analysis is whether the energy form provided by the technology (in this case, electricity) is of sufficient benefit to society to warrant the investment of limited resources. Since the technologies to be compared are all electricity gener- 
ators, the question falls outside the scope of this analysis and the issue becomes one of evaluating alternative ways of providing that electricity.

Units of Measure

Ideally, the measure of energy investment in a system would include the energy required for the following: provision of materials for system construction, construction of the facilities, provision of process materials used in operating the system, and operation of the system. These energy requirements would be compared with the primary input, losses, and useful energy output of the system. Because of the complexity of the analysis, it is not possible to assemble this information on a consistent basis. In some instances the measure of energy flow is the result of direct field experience with units in operation or at least with laboratory-scale experiments. In other cases, particularly with respect to materials energy requirements; data on the energy flow are derived and based on surrogate parameters such as cost. It will not be possible, in the scope of this assessment, to generate a completely consistent and comprehensive data base for the energy flows.

It would also be desirable to maintain distinctions among various forms of energy (e.g., electricity, fuels, heat, radiation, etc.) so as to account for the varying quality of each. This will not be entirely possible, again due to the potential complexity of the analysis and the lack of comprehensive information.

Thus, the measure of energy flow will be consistent with respect to units (e.g. joules/year), but the data will reflect different degrees of accuracy in their derivation.

The measure of efficiency of resource utilization is a ratio of the energy output to the resource input. A number of alternative efficiency ratios can be formed using different combinations of the energy flows. The most meaningful will be identified in the course of the analysis.

The measurement of payback period is simply an integration of the energy flows over time. Ideally, the energy flows would be computed as functions of time, considering items such as start-up times, construction time lags, and system deterioration. In practice, however, these data are not easily computed, and the analysis will have to use information averaged over the lifetime of the system. 
The final measure of the suitability of the rate of energy return on investment will be strictly a comparison of the return from the various alternatives considered. Since many other variables enter into the final decision on suitability, the only evaluation to be conducted here is a comparison of SPS to other systems.

\section{Methods}

There are basically three forms of net energy analysis that can be employed. A Battelle study 46 gives a concise review and critique of the alternatives. Process analysis, which involves a detailed balance of energy flows into and out of a system, is the most accurate and most involved form of assessment and can be applied to situations where a great deal of processspecific information exists. Input-output analysis uses an analogy to economic input-output analysis to determine the energy "custs" of any energy supply. It involves an Identification of the interactions among all sectors of the economy required to produce energy and a translation into energy equivalents of the flow of goods and services among sectors. Ecoenergetics analysis, which can be compared to a cost/benefit analysis, involves the assignment of energy values to various portions of the natural environment that are affected by the energy system.

For this study, a combination of process analysis and input/output analysis will be employed; the ecoenergetics approach will not be used. Process analysis will be used where the energy flow data are detailed and are derived from field experience, which is generally the case when dealing with the performance characteristics of various pieces of equipment in the technology stream. The input/output analysis will be used to determlue the energy investment in materials and construction. It is the only mechud tliat can bc applied with a reasonable expenditure of effort when considering the complex interactions and energy flows throughout the ecuuming that. arc involved in delivery of a given quantity of materials. The method accounts for economic transactions and uses an energy intensity measured in Btu/\$ to convert the cost transactions lo energy flows. This procedure has been used in a number of other technology analyses. 
Data Bases

There is a wealth of data available on the performance characteristics of various systems of electricity generation. Even for the SPS, which is one of the least well-defined because of its relatively recent proposal, the NASAand contractor-developed system definitions provide adequate information for a net energy analysis. These data are useful in the process analysis procedure as applied to direct energy flows through the systems.

For the analysis of the energy required in the materials and construction, the data are more sketchy and less consistently presented. In some cases, the materials requirements are stated in physical quantities, in other cases, only in terms of costs. This is not an especially difficult problem since all materials requirements can be converted to cost equivalents to apply the input/output methodology.

Data for the input/output analysis (i.e., economic sector values for $B t u / \$$ of material product) are derived from the work of Herendeen and Bullard.47 Many modifications and perturbations 48 have been made to the basic information generated in that work, but it remains the most widely used data base for net energy analysis. Kotin 42 is a source for energy data on SPS. Data for process energy consumption will be drawn from a number of. sources (Refs. 49-51).

Wherever possible, data from other net energy analyses of similar or closely related systems will be used to shorten the time requirements for obtaining a preliminary analysis. This may lead to some inconsistencies, and evaluations will be made to determine if the data from prior analyses are adequate.

\subsubsection{Water Resources}

The objective of the water resources analysis is to determine the quantity of water used. (consumptive and nonconsumptive) and the quality of water returned during the complete tuel cycles of the SPS and alternative technologies.

\section{Issue Description}

Water is utilized to varying degrees in nearly all electrical energy production activities, including raw material extraction and processing, 
reclamation of mined land, component fabrication, transportation, construction, on-site processing and cooling, and waste disposal. The central issues for comparing the water resource impacts of alternative energy systems (side-by-side analysis) are (1) total withdrawal requirements, (2) consumptive requirements (the portion of water utilized that is not-returned), and (3) quality of the water utilized and returned (changes in chemical, thermal, and radioactive constituents).

The overall significance of the relative differences in withdrawal, consumption, and quality parameters only becomes apparent through consideration of the availability of regional water resources and the competing natural and societal uses of that resource. Thus an evaluation of the water resource requirements for anticipated levels and geographical distribution of energy processes is also required (alternative tutures analysis).

\section{Units of Measure}

The units of measure for conducting the side-by-side analysis of water resource impacts are obtained directly from the characterizations to be provided for each of the activities within the energy production system (i.e., mining, reclamation, generation, component fabrication). The principal parameters in this analysis are listed in Table 3.6. These parameters must also include regional sensitivity to factors such as evaporation rates and precipitation-dependent, non-point run-off.

The consumptive water requirements are not ultimate losses from the global system but are rather changes in the geographical distribution and availability of the resource. For this reason, the units of measure in Table 3.6 distinguish between evaporative losses, which are those from the immediate basin from which the water was extracted, and discharges to groundwater, which may replenish local supplies.

The alternative futures analysis of water resource impacts requires delineation of the regional availability and quality of water resources for energy production. The available parameters to be utilized for this analysis are given in Table 3.7. The basic geographical units for this analysis are the Water Source Council Aggregated Subareas (ASAs).52. The boundaries of the 100 ASAs in the U.S. follow county boundaries so as to approximate the boundaries of the major hydrologic basins. A major shortcoming in the param- 
Table 3.6 Units of Measure ${ }^{a}$ for Water Resource Requirements and Impacts of Energy Systems

Withdrawal

Consumption

Process requirement's

Cooling requirements

Waste disposal requirements

Evaporative losses - total

Discharge to groundwater - total

Returned surface-water characteristics

Volume

Temperature

Radioactivity

Chemical pollutants

Treated

Untreated

Groundwater discharge characteristics

a Normalized per unit of output power or energy

(e.g., 1 MWe or 1 MWe-yr).

Table 3.7 Units of Measure for Regional Availability and Quality of Water for

Energy Production

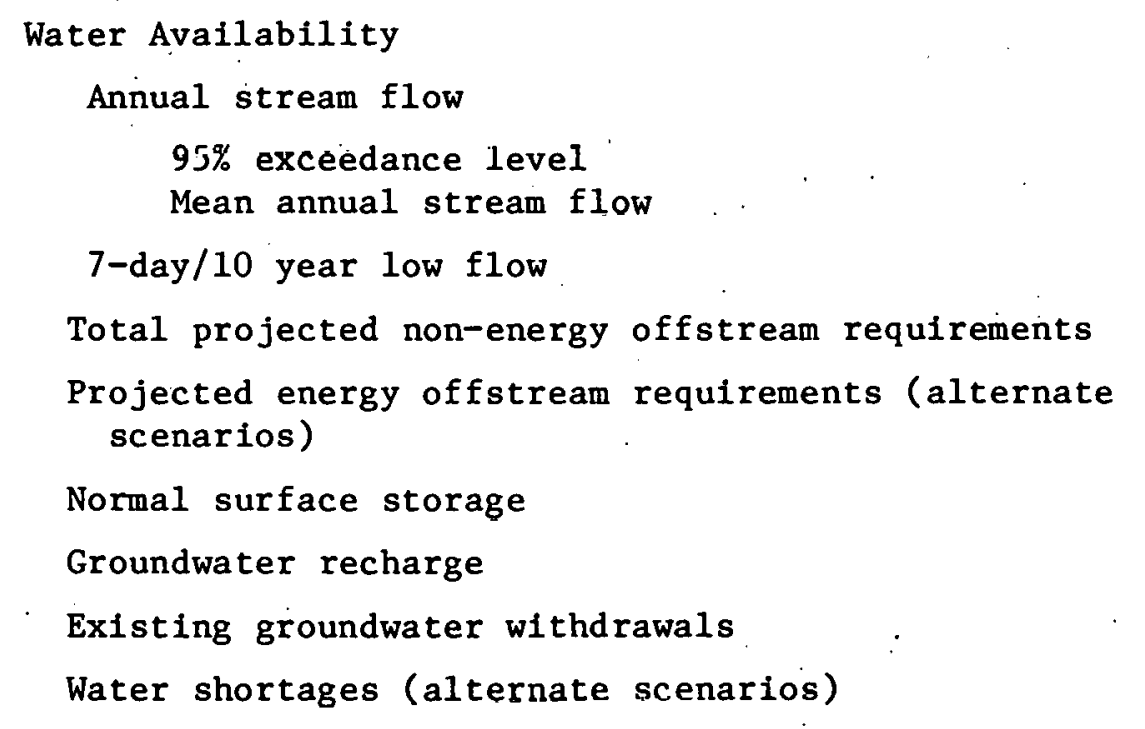


eters of regional water availability is the inadequate definition of cumulative instream water requirements for aquatic ecosystems, recreation, and hydropower. These instream requirements have been established by planning agencies in only selected areas. In the absence of explicit instream requirements a common practice has been to assume that certain historical low flow levels are to be maintained. Examples are $90 \%$ of the 7-day-average low flow that occurs statistically every 10 years (7-day/10-year flow) and the annual stream flow statistically exceeded 95 years out of each 100-year period (95-percent annual flow exceedance).

Table 3.7 also lists as a parameter the surface storage that can be used for a limited period to augment supplies during low fl nw conditions. Subsurface supplies can also be used to augment water resources; however data on these supplies are not available in detail, and it is a conservative estimate that these groundwaters should not be depleted at a rate larger than the recharge rate, which is included as a unit of measure in Table 3.7.

\section{Methods}

The preliminary evaluation will be a side-by-side evaluation based primarily on the water use and quality parameters 1isted in Table 3.7 for al1 activities associated with unit energy production within the alternative energy systems. Subsequent analysis wit11 delermine the water consumption and withdrawal impacts of the alternative cechulugies in arcao with water shortages or critically limieed water avallability, as identified in previous extensive analyses of various energy scenarios. The approach to be used is to replace the technologies within those areas with the alternatives defined in this study, and to determine the level to which the water avallability problems will be alleviated or exacerbated. The level of replacement by alternative terhnologies will be designed to be consistent with the overall allernative futures analysis.

\section{Data Bases}

The most extensive and current data for use in the regional water avallability analysis is that compiled by the Water Resources Council in the Second National Water Assessment. 52 This reference contains detailed data on 
surface-water flows, groundwater aquifers, and current and projected use by various sectors, including energy development. This data has been used as a basis for evaluating water requirements and constraints for various energy scenarios devised by DOE and other agencies. 53,54

\subsubsection{Comparative Labor Effects}

The objective of the labor analysis is to assess the supply and demand characteristics of various types of skills needed for the SPS and alternative energy technologies. The concern here is not merely with the numbers of persons required in each category, which is an employment question, but current and likely trends influencing the availability of persons with specific skills.

It is important that the choice of an energy technology closely match available skills. If likely deficiencies are determined, then measures must be taken ahead of time to develop the skills required. It might also be desirable to avoid a surplus of certain skills with resultant underutilization of the work force.

For example; these concerns would arise during the choice of a "high technology" over one requiring less sophisticated skills. If the trend toward a more highly educated work force continues, there may be increased reluccance on the part of members of the work force to enter careers that they feel are not challenging. In such a situation, the choice of a high technology may result in better utilization of available labor because it promises more challenging work, better job satisfaction, and more fulfilling careers.

\subsection{ECONOMIC AND SOCIETAL IMPACTS}

\subsubsection{Macroeconomic Effects}

The purpose of the macroeconomic assessment is to compare the impact that the SPS and the energy alternatives will have on the U.S. economy of the 21 st century at the national, regional, and income class levels. Because of the large expenditures involved in satisfying power growth requirements, there may be significant differences among the systems in their effects on such macrovariables as GNP and inflation. 


\section{Units of Measure}

The units of measure at the national level are the differential effects on GNP growth, employment, inflation rates, interest rates, and foreign trade balances. Effects on taxes or government debt or on both will be analyzed in the context of the type of system ownership postulated, that is, federallyowned systems could be expected to be associated with taxes and/or national debt higher than comparable privately-owned systems.

Me.thods

The major components of a macroeconomic comparative assessment include the following:

- Aggregation of direct and indirect costs that would be estimated in connection with the assessments of costs and performance, resources, and socloeconomic and welfare issues.

- Selection of (an) appropriate macroeconomic/energy model(s) to be used for assessment purposes.

- Specification of ground rules and policy inputs for the model(s). For example, such specifications would include ownership mode, degree of government financing, total national capacity, and utilization factors.

- Exercise of the assessment model(s) and interpretation of results.

Although difficult, rough estimates of direct and indirect system costs can be developed and aggregated into macro-inputs to the model. For example, indirect costs due to resource depletion may be partially estimated by reference to coal and uranium supply curves included in the SRI-Gulf 55 energy mode1, which extends to 2025 .

A fundamental problem is the selection of an appropriate assessment model from existing models that are mostly based on partial equilibrium. For example, macrovariables are inputs to the PIES56 model, which can then determine equilibrium energy prices and quantities. But these prices and quantities do not affect the original inputs. Thus, PIES does not capture the feedback effect of energy prices that can affect the economy. (It is widely believed that the 1974 recession was triggered by massive increases in oil prices.) 
Fortunately, the Hudson-Jorgenson, 57 PILOT 58 and ETA-MACRO ${ }^{14}$ (which extends to 2050) models use a general equilibrium approach. Consequently, these models will be evaluated for use in the assessment. Specifically, results from the "Energy Forum" project at Stanford University (sponsored by EPRI) will be used. In the "Forum" effort, various energy/economics models were tested using comparable inputs and ground rules. Differences in results were either reconciled or compared, and on the basis of these comparisons, some judgments can be made on the merits of the various models.

Specification of ground rules for the assessment models will strongly affect the results obtained. Accordingly, several sets of ground rules corresponding to several future scenarios w1ll be defined. For example, if the economy is postulated to be at less than a full-capacity utilization level, new system expenditures should increase GNP and employment. Further, such increases could be estimated by use of Keynesian multipliers. On the other hand, a full-capacity utilization scenario would imply either "crowding out" of other ventures to permit power financing or an increase in the economy's savings rate, in which case, neoclassic growth models 59 would be appropriate for assessment purposes. (In neoclassic models, economic growth trajectories are, generally, functions of the growth and productivity increase of labor, the relationship of output to the mix of labor and capital, and the growth rate of capital that arises from diversion of output to capital.)

Considering that the structure of most macroeconomic models is based on historical time series, projections of results to the post-2000 era will require caution. Relative rather than absolute results will be stressed, and sensleivity to scenarios will be examined closely.

Data Bases

Basically two types of data will be required for macroeconomic assessment. One type will include direct and indirect system costs and will be generated as a by-product of comparative assessments in the areas of cost and performance, resources, socioeconomics and welfare. The other type of data will entail possible trajectories of the economy without SPS and its alternatives. These economic trajectories are scenarios that will be defined in a forthcoming scenario development effort. Finally, a great deal of specialized information on energy and power is available from the data bases that support such models as ALPS 60 and BESOM. 61 


\subsubsection{Socioeconomic Impacts}

The purpose of the socioeconomic assessment is to evaluate regional differences in economic and societal gains and losses due to the development and deployment of alternative energy technologies and to compare these effects with those due to a satellite power system. Important factors pertinent to this evaluation include the stimulus to regional employment and growth, indirect industrial growth, secondary growth, and population and industrial migration.

\section{Issue nesoription}

The growing trend toward political pluralism has 1ts cuunteipait in the observed trend toward decentrallzation and what John Naisbitt hac termed geographic pluralism. 62 As the states have begun to move in the direction of garnering increased control over their own destinies by challenging the federal government in areas once considered its sole preserve (e.g., energy and environmental regulation), new coalitions and organizations of states have been formed along regional boundaries. According to Naisbitt, these regional political organizations have grown out of the concern of individual states for the widening differences in economic growth and demographic change among certain regions of the country.

It is into this climate of intensifying regionalism that the debate over alternative electric power technologies will be thrust. With the frostbelt, sunbelt, and intermountain west vying with the federal government over energy policy and with each other over the issue of state and regional growth and development, it seems imperalive that an assessment of the impacts of these alternative energy options be conducted to examine the relative regional economic and demographic advantages and disadvantages that these options are likely to impose. Sperifically, the following issues need to be explicitly addressed in order to determine the effects of alternative energy options on regional growth and development goals:

1. An identification of baseline demographic and economic trends within regions.

2. A determination of regional growth and development goals.

3. The stimulus to employment and population growth provided by each technology within the regions. 
4. The effect of this stimulus on future industrial growth and development among regions.

5. The changes in inter-regional population and industrial migration likely to accompany each major energy option.

Units of Measure

The analysis of comparative regional economic and societal effects will be largely quantitative. Trends in regional economic and demographic changes will be made with the aid of acceptabie estimates for the period up to and beyond 2000. The stimulus to employment and population change will also be estimated empirically with existing models developed for comparative assessments of technologies. The effect of the stimulus of energy. development and avallability on industrial and population relocation will be treated less quantitatively. Much of the information for assessing these specific impacts will be obtained from the existing literature and will be used to construct hypothetical patterns that can be used to judge the probable range of regional economic and demographic changes likely to accompany each energy technology.

\section{Methods}

The assessment of the regional approach and societal effects will utilize a "bottom-up" approach. The analysis could be carried out with the aid of compulational cools like. the Social and Economic Assessment Model (SEAM).63 These w111 be applied to a "typical" electricity supply facility in a "real world" environment. Given the employment characterization of a typical facility and its probable site, the following information will be generated:

1. Baseline characteristics of the size and composition of the population in the surrounding areas.

2. Employment characteristics of the population.

3. Annual employment requirements in the energy facility and expanded commercial and retall sectors.

4. Annual job-1nduced changes in the population of the area.

5. Effects on community infrastructure of these changes (if any) in population. 
This analysis will be conducted for typical energy supply facilities for each technology in several typical sites with different characteristics (e.g., size, economic base). Given this information on the localized or site-specific economic and social changes accompanying the introduction of these various technologies, the regional economic and societal effects will be extrapolated and compared across regions for each technology.

This extrapolation of socioeconomic effects will be based on the "observed" impacts of each technology in different settings, a reasonable siting scenario for each of the technologies, and the relationship of electrical energy supply to the inducement of industrial relocation. For example, If a given technology is appropriately sited in only two or three major regions (e.g., OTEC) and its economic and societal effects are estimated to be large in specific sites, the effects on regional growth and development and the consequences for population shifts among regions might be judged to be substantial. If, in addition, the availability of electrical energy in these reglons would cause specific industries to relocate, the effects on interregional population and economic growth and change would be magnified. Although specific analyses of the relationship between the availability of power and Industrial location decisions are beyond the scope of this study, alternative scenarios can be developed to demonstrate the effects of varying industrial relocation possibilities that are consistent with the findings in the available literature.

\section{Data Bases}

The data required to conduct this assessment will come from the following primary sources:

- Computational models, 11ke the SEAM,63 which include extensive data bases of their own.

- SPSS societal assessment data frum thé CDLil.

- Satellite and terrestrial systems characteristics (e.g., employment requirements, reglonal siting information, and, materials requirements).

\subsection{INSTITUTIONAL IMPACTS}

The purpose of the assessment of institutional effects is to investigate the potential impacts of energy technology deployment and operation on regulatory agencies and the reciprocal impact of the latter on energy tech- 
nology deployment and operation. The principal issues that must be investigated include the following:

- The Impact of local, state, federal, and international regulations on the cost and flexibility of a technology.

- The extent to which regulatory policies may have to be altered to accommodate new regulatory problems created by a technology, including the likely cost and purview of regulatory agencies, which may be formed to control these new concerns.

- The extent to which new initiatives required to effectively regulate a new technology harmonize with the needs of existing nonregulatory governmental institutions.

- The extent to which new federal institutions created to effectively regulate a new technology harmonize with the needs of nongovernmental institutions.

Units of Measure

The comparative institutional assessment will of necessity be qualitative, and the selection of particular measures will depend on the type of institutional effects being assessed and the methods that are applied. Because institutions tend to respond to perceived problems resulting from a new technology, the measurements in this comparison will depend to a large extent on the measurements utilized in other sections of this study. Costs of regulation and regulatory delay will be quantified to the greatest extent possible.

\section{Methods}

The relationship between each technology and the institutions that may affect it will be identified from the impact data determined in other parts of this study. The possible involvement of existing institutions at local, state, federal, and international levels will be surveyed on the basis of existing formal and informal jurisdictions. The possible need for new regulatory authority or new agencies will be assessed in comparison to historical precedents and developing regulatory trends.

In the process of this survey, laws, regulations, administrative codes and guidelines, and other legal constraints on the implementation of large-scale energy technolingies will bc cross-referenced and catalogued. To the extent that they can be identified, particular laws affecting the specific technologies that are being compared should also be evaluated. 


\section{THIS PAGE}

WAS INTENTIONALLY

LEFT BLANK 


\section{REFERENCES}

1. U.S. Department of Energy and NASA, SPS CDEP Reference System Report, DOE/ER-0023 (October 1978).

2. Hittman Associates, Inc., Environmental Impacts, Efficiency, and Cost of Energy Supply and End Use, Vol. I (November 1974) PB-238 784, and Vo1. II (January 1975) PB-239 159, available from NTIS, Springfield, Va.

3. Council on Environmental Quality, MERES and the Evaluation of Energy Alternatives, Stock number 041-011-0026-2, U.S. Government Printing office, Washington, D.C. (May 1975).

4. University of Oklahoma, Science and Public Policy Program, Energy Altematives: A Comparative Analysis, prepared for the Council on Environmental Quality, Stock number 041-011-00025-4, U.S. Government Printing Office, Washington, D.C. (May 1975).

5. Caputo, R., An Initial Comparative Assessment of Orbital and Terrestrial Central Power Systems, Jet Propulsion Lab, 900-780 (March 1977).

6. Hub, K.A., et al., A study of Social Costs for Altermative Means of Electrical Power Generation for 1980 and 1990, Argonne National

Laboratory Report ANL-8092 (February 1973).

7. Mitre Corporation, METREK Division, System Descriptions and Engineering Costs for Solar-Related Technologies, Volumes I-IX, MTR-7485 (June 1977).

8. Energy Policy Project of the Ford Foundation, A Time to Choose: America's Energy Future, Ballinger Publishing Co., Cambridge, Mass. (1974).

9. Hilson, Cailull L., project director, t'nergy: Global Prospects 1985-2000, Report of the Workshop on Alternative Energy Strategies (WAES), McGraw-Hill, New York, N.Y. (1977).

10. Wilson, Carroll L., project director, Energy Supply-Demand Integrations to the Year 2000, MIT Press, Cambridge, Mass. (1977).

11. Foell, W.K., ed., Proceedings of the 1978 Conference on Altermative Energy Futures for Wisconsin, Wisconsin Office of State Planning and Energy, Madison, Wis. (1978).

12. Meadows, D.H., et al., The Limits to Growth, Potomac Associates, Washington, D.C. (1972).

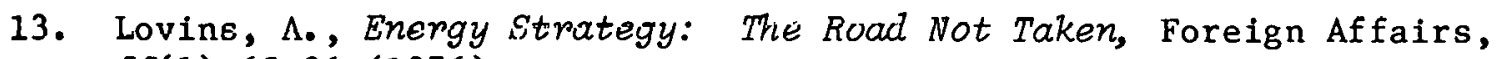
$55(1): 65-96$ (1976).

14. Lovins, A., Soft Energy Paths: Toward a Durable Peace, Ballinger Publishing Co., Cambridge, Mass. (1977). 
15. Energy Modeling Forum, Energy and the Economy, Electric Power Research Institute Report EPRI EA-620, Palo Alto, California (1978):

16. Manne, A.S., Energy-Economy Interaction: An Overview of the ETA-MACRO Model, Energiespectrum (November 1977).

17. Buehring, W.A., W.K. Foell, and R.L. Keeney, Examining Energy/Environment Policy Using Decision Analysis, Energy Systems and Policy, 2(3):341-367 (1978).

18. Bierman, H., and S. Smidt, The Capital Budgeting Decision, 2nd ed., The Macmillan Co., New York (1966).

19. Grant, E.L., and W.G. Ireson, Principles of Engineering Economy, 4th ed., Ronald Press Co., New York (1960).

20. Cumuunwealth Edicon Company, Enginepring Ficonomico, Communwealth Edison Company, Chleagu (1975).

21. Mishan, E.M., Cost-Benefit Analysis: An Introduction, Praeger, New York (1971).

22. Prest, A.R., and R. Turvey, Cost Benefit Analysis: A Survey, The Economic Journal, $15(300): 683-735$ (1965).

23. Fischhoff, B., Cost-Benefit Analysis and the Art of Motorcycle Maintenance, Oregon Research Institute,. ORI Research Monograph, Vo1. 16, No. 1

(January 30, 1976).

24. Baecher, G. B., et a1., Balancing Apples and Oranges: Methodologies for Facility Siting Decisions, Report No. RR-75-33, International Institute for Applied Systems Analysis, Laxenburg, Austria (September 1975).

25. Dean, B.V., and M.J. Nishry, Scoring and Profitability Models for Evaluating and Selecting Engineering Projects, JOR3A, 13(4):550-570 (1965).

26. Gaurguilo, G.R., et al., Developing Systematic Procedures for Directiny Research Programs, IRE Transactions on Engineering Management, Volume EM-7, pp. 2-7 (1960).

27. Fishburn, P.C., Utility Theory, Management Science, 14(5):335-378 (1968).

2.8. E. I. DuPont de Nemours and Co. DuPont Guide to Venture Analysis (1971).

29. Rudd, Dale F., and Charles C. Watson, Strategy of Process Engineering, John Wiley and Sons, New York (1968).

30. Brown, Rex V., Andrew S. Kahr, and Cameron Peterson, Decision Analysis for the Manager, Holt, Rinehart and Winston, New York (1974).

31. Keeney, Ralph L., and Raiffa, Howard, Decisions with Multiple Objectives: Preferences and Value Tradeoffs, John Wiley and Sons, New York (1976). 
32. Stanford Research Institute, Decision Analysis Group, Readings in Decision Analysis, Palo Alto, Calif. (1974).

33. Electric Power Research Institute, Synthetic Electric Utility Systems for Evaluating Advanced Technologies (February 1977).

34. Regional Power Planning: A State-of-the-Art Assessment, University of Oklahoma (January 1978).

35. Ezzati, Ali, Economic Analysis of Advanced Energy Technologies:

Proceedings of Engineering Workshop, April 4-5, 1977, MITRE TR7611 (August 1977).

36. EPRI 1977 Technical Assessment Guide, revised, EPRI PS-866-SR (June 1978).

37. Westinghouse, A Methodology for Solar-Thermal Power Plant Evaluation, prepared for EPRI, EPRI ER-869 (August 1978).

38. Morris, S.C., and K.M. Novak, Databook for the Quantification of Health Effects from Coal Energy Systems, Biomedical and Environmental Assessment Division, Brookhaven National Laboratory, Upton N.Y. (1977).

39. Reactor Safety Study: An Assessment of Accident Risks in U.S. Commercial Nuclear Power Plants, WASH-1400 (NUREG 75/014), October 1975.

40. Gallagher, J.M., et al., Resource Requirements, Impacts and Potential Constraints Associated with Various Energy Futures, PAE/3794-6, Bechtel Corporation, San Francisco (March 1977).

41. MERES and the Evaluation of Energy Altematives, Council on Environmental Quality (May 1975).

42. Kotin, $\Lambda_{.}$.., SFS Resource Kequirements (Critical Materials, Energy, and Land), HCP/R-4024-02, U.S. Department of Energy (October 1978).

43. Mineral Facts and Problems, Bureau of Mines, U.S. Department of the Interior, Washington, D.C. (1976).

44. Brobst, D.A., and W.P. Pratt, eds., United States Mineral Recources, U.S. Geological Survey Professional Paper 820, U.S. Government Printing Of fice, Washington, D.C. (1973).

45. Watts, R.L., et al., Some Potential Material Supply Constraints in the Deployment of Photovoltaic Solar Electric Systems, Pacific Northwest Laboratory, Richland, Wash. (September 1978).

46. Fraley, D.W., C.L. McDonald, and N.E. Carter, A Review of Issues and Applications of Net Energy Analysis, Draft Report, Battelle Pacific Northwest Laboratories (September 26, 1977). 
47. Herendeen, R.A., and C.W. Bullard III, Energy Costs of Goods and Services, 1963 and 1967, CAC Document No. 140, Center for Advanced Computation, University of Illinois at Urbana-Champaign (November 1974).

48. Frabetti, A.J. Jr., et al., Application of Net Energy Analysis to Consumer Technologies, DSI Report No. 047, Development Sciences, Inc. (December 22, 1976).

49. Livingston, F.R., et al., Satellite Power System (SPS) Preliminary Resource Assessment Report No. 900-805, Rev. A, Jet Propulsion Laboratory (August 7, 1978).

50. Herendeen, R.A., Two Technologies Near the Net Energy Limit: Gasohol and Solar Satellite Power Station, Energy Research Group, University of Illinois at Urbana-Champaign (August 1978).

51. Gandel, M.G., et al., Assessment of Large-Scale Photovoltaic Materials Production, Report No. EPA-600/7-77-087, U.S. Environmental Protection Agency (August 1977).

52. The Nation's Water Resources, The Second National Water Assessment, Water Resources Council (draft, March 1978).

53. National Coal Utilization Assessment, Project Plant 1977-1979, ERDA 77-19 (March 1977). A series of regional reports are available through this program, which includes water resource analysis for energy development.

54. Harte, J., and M. E1-Glassier, Energy and Water, Science, 199 (4329) (February 10, 1978).

55. Cazalet, E.G., Generalized Equilibrium Modeling: The Methululogy of the SRI-Gulf Energy Model, Decision Focus Inc. (May 1977).

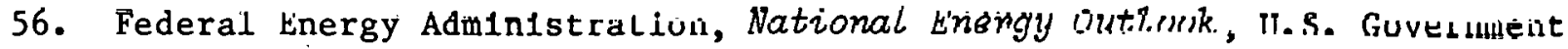
Printing office (February 1976).

57. Hudson, E.A., and Jorgenson, D.W. U.S. Eneryy Puliciy arut Esonomio Crowth 1975-2000, Bell J. Econ. Mgt. Sci 5:461-514 (1974).

58. Dantzig, G. $\bar{B}$., et al., Stanfurd FILOT Energy/Eoonomic Model., Elertrir. Power Research Institute, Report EA-626 (1978).

59. Allen, R.G.D., Macro-Economic Theory, Macmillan, New York (1968).

6U. Hard1e, R.W., et al., ALPS, A Linkar Trngramming System for Forecasting Optimum Power Growth Patterms, Hanford Engineering Development Laboratory (April 1972).

61. Hoffman, K.C., A Unified Fromework for Energy Systems Planning, in Energy Modeling, Resources for the Future (March 1973).

62. Naisbitt, John, Satellite Power System (SPS) Centralization/Decentralization, HCP/R-4024-09, U.S. Department of Energy (September 1978).

63. Stenehjem, E.J., Summary Description of SEAM: The Social and Economic Assessment Model, ANL Technical Report, ANL/IAPE-TM-78-9 (April 1978). 


\section{BIBLIOGRAPHY}

Health and Safety Effects

occupational Injuries and Illnesses in the U.S. by Industry 1975, U.S.

Department of Labor, Bureau of Statistics, 非1981 (1978).

Environmental Protection Agency, Strategic Environmental Assessment System (SEAS) Model.

Environmental Protection Agency, Health Consequences of Sulfur Oxides - A Report from Chess 1970-1971, EPA 650/1-74-004.

Buechley, R.W., et al., $\mathrm{SO}_{2}$ Levels and Perturbations in Mortality , Archives of Env. Health, 27(3) (Sept. 1973).

Lave, L. B., and E.P. Seskin, Air Pollution on Human Health, Johns Hopkins University Press, Baltimore (1977).

Union of Concerned Scientists, Preliminary Review of AEC Reactor Safety Study, Cambridge, Mass. (1974).

National Academy of Sciences (BEIR), The Effects on Populations of Exposure to Low Levels of Ionizing Radiation. Report on the Advisory Committee on the Biological Ef fects of Ionizing Radiations. Division of Medical Sciences NAS/NRC (November 1972).

Sagan, L. A., Health Costs Associated with the Mining, Transport and Combustion of Coal in the Steam Electric Industry, Nature, 250:107-111 (1974).

Inhaber, H., Risk of Energy Production, Atomic Energy Control Board, P.0. Box 1046, Ottawa, Canada KIP 5S9 (1977).

Comer, C.L., and L.A. Sagan, Health Effects of Energy Production and Conversion, Annual Review of Energy, 1:581-599 (1976).

Lave, L. B., and L.C.' Freeburg, Health Effects of Electricity Generation from Coal, Oil and Nuclear Fuel, Nuclear Safety, 14:409-428 (1973).

Salmon, L. B., Comparative Assessment of Health, Safety, and Environmental Impacts of Coal Use, for DTA/OTI, (Draft, Oct. 1978).

Economic and Societal Impacts

Cohen, S., et al, Selection Criteria for Synthetic Fuels Commercial Demonstratation Program, TRW (June 1976).

Synfuels Interagency Task Force, Recommendations for a Synthetic Fuels Commer cialization Program, Vol. II, Appendix D, U.S. Government Printing office Washington, D.C. (November 1975). 
Economic and Societal Impacts (Cont'd)

Rink, R., and A. Ford, BOOM-H: A Simulation Model for Boomtown Housing, Los Alamos Scientific Laboratory LA-7324-MS (September 1978).

Comparative Institutional Effects

Political and Legal Implications of Developing and operating a SPS, Final Report, ECON, Inc., Princeton, N.J. (August 15, 1977).

Jones, William K., Regulated Industries: Cases and Materials, Foundation Press (1976).

Satellite Power System (SPS) State and Local Regulatinns as Applied to Satellite Power System Microwave Receiving Antenna Facilities, HCP/R4024-05, Allan D. Kotin, DOE/NASA, Satellite Power System Concept Development and Evaluation Program (October 1978). 
United States

Department of Energy

Washington, DC 20585
Postage and Fees Paid U.S. Department of Energy DOE-350



FIRST CLASS MAIL

Penalty for Private Use, $\$ \mathbf{3 0 0}$ 